\title{
Bioethanol Upgrading to Renewable Monomers Using Hierarchical Zeolites: Catalyst Preparation, Characterization, and Catalytic Studies
}

\author{
Ploychanok Iadrat ${ }^{1}$ (D) and Chularat Wattanakit ${ }^{2, *}$ \\ 1 School of Molecular Science and Engineering, Vidyasirimedhi Institute of Science and Technology, \\ Rayong 21210, Thailand; ploychanok.i_s17@vistec.ac.th \\ 2 School of Energy Science and Engineering, Vidyasirimedhi Institute of Science and Technology, \\ Rayong 21210, Thailand \\ * Correspondence: chularat.w@vistec.ac.th; Tel.: +66-033014255
}

check for updates

Citation: Iadrat, P.; Wattanakit, C. Bioethanol Upgrading to Renewable Monomers Using Hierarchical Zeolites: Catalyst Preparation, Characterization, and Catalytic Studies. Catalysts 2021, 11, 1162. https: / / doi.org/10.3390/ catal11101162

Academic Editors: Stefania Albonetti, Tommaso Tabanelli and Nikolaos Dimitratos

Received: 26 August 2021

Accepted: 23 September 2021

Published: 26 September 2021

Publisher's Note: MDPI stays neutral with regard to jurisdictional claims in published maps and institutional affiliations.

Copyright: (c) 2021 by the authors. Licensee MDPI, Basel, Switzerland. This article is an open access article distributed under the terms and conditions of the Creative Commons Attribution (CC BY) license (https:/ / creativecommons.org/licenses/by/ $4.0 /)$.

\begin{abstract}
Bioethanol is one of the most promising renewable resources for the production of important monomers. To date, there have been various processes proposed for bioethanol conversion to renewable monomers. In this review, the catalytic bioethanol upgrading to various types of monomers using hierarchical zeolites as catalysts is illustrated, including the recent design and preparation of hierarchical zeolites for these catalytic processes. The characterizations of catalysts including textural properties, pore architectures, acidic properties, and active species are also exemplified. Moreover, the catalytic studies with various processes of monomer production from bioethanol including bioethanol dehydration, bioethanol to hydrocarbons, and bioethanol to butadiene are revealed in terms of catalytic activities and mechanistic studies. In addition, the future perspectives of these catalytic circumstances are proposed in both economic and sustainable development contexts.
\end{abstract}

Keywords: bioethanol upgrading; renewable monomers; hierarchical zeolites; light olefins

\section{Introduction}

Monomers are important raw materials in polymer industries as they can react together to build polymers via polymerization processes [1]. Typically, the conventional production of monomers has been performed via petroleum-based processes using high temperature conditions and fossil resources such as thermal cracking of saturated hydrocarbons [2]. Currently, there are problems of fossil fuel depletion [3,4] and environmental and global warming concerns caused by greenhouse gases released from the petrochemical industries $[5,6]$. Therefore, the corresponding production from renewable resources has been considered as an alternative way to solve these issues.

Bioethanol is a well-known biomass resource, which can be produced by the fermentation process of various biomass resources, such as sugar cane, cassava, wheat, and corn $[7,8]$. The quantity of global bioethanol production is increasing year by year and it is expected to continuously grow in the future [9]. Presently, bioethanol has been mainly used as a biofuel for transportation [10]. However, the novel technology of the electric vehicle (EV) has been considered to replace the conventional vehicle in the near future [11,12]. Consequently, the demand of biofuel will be reduced. To open up the options for further uses of bioethanol, the conversion of bioethanol to high value-added chemicals is required.

For the above-mentioned reasons, the bioethanol upgrading to renewable monomers is very interesting and promising. There have been various processes for the production of monomers from bioethanol, such as bioethanol dehydration to ethylene [13], bioethanol conversion to hydrocarbons [14], and bioethanol to butadiene [15]. Remarkably, the ethylene production from bioethanol dehydration is an alternative process using the renewable resource instead of fossil resources, which can reduce greenhouse gas emission 
and create a more environmentally friendly process, and it has been already available in the commercial scale in some locations, for example, Brazil [16]. Notably, the heterogeneous catalysts that are required in these processes include activated alumina, zinc aluminates, zirconium oxide, magnesium oxide, silicon oxide, and zeolites $[17,18]$. Among them, a zeolite is one of the most promising catalysts because of its various suitable properties, such as shape selectivity, ion-exchange capability, acidic properties, and high surface area [19]. However, the conventional zeolites frequently suffer from the mass transfer limitation, leading to fast catalyst deactivation because of micropore blocking by coke species [20]. To overcome this drawback, hierarchical zeolites have been proposed.

Hierarchical zeolites are composed of at least two classes of pore structures. There are three classes of porous systems, including micropores (pore diameter or $D_{p}<2 \mathrm{~nm}$ ), mesopores $\left(D_{p}=2-50 \mathrm{~nm}\right)$, and macropores $\left(D_{p}>50 \mathrm{~nm}\right)$ [21]. The additional mesopores and/or macropores of hierarchical zeolites can reduce the diffusion path length, resulting in longer catalyst lifetime compared to a conventional zeolite [20]. Currently, there have been three main types of hierarchical zeolites, including zeolite nanosheets, nanosized zeolites, and mesoporous zeolites [20]. However, the design of hierarchical zeolite catalysts strongly depends on the reaction applications because different reactions require distinct active species.

In this review, the preparation, characterization, and catalytic studies of hierarchical zeolites for bioethanol upgrading to various monomers are presented. In Section 2, the design and preparation of hierarchical zeolite catalysts are divided into three categories, including the zeolite synthesis via bottom-up and top-down approaches and the metal incorporation into zeolite supports. For Section 3, the characterization of hierarchical zeolite catalysts, which can be classified into two groups: (i) textural properties and pore architecture; (ii) acidic properties and active species, is demonstrated. Finally, the catalytic behaviors of hierarchical zeolites in bioethanol conversion to monomers are divided into the catalytic activities and mechanistic studies in the bioethanol dehydration, bioethanol to hydrocarbons, and bioethanol to butadiene reactions.

\section{Design and Preparation of Hierarchical Zeolite Catalysts}

The preparation of hierarchical zeolite catalysts can be divided into three strategies including a bottom-up approach, a top-down approach, and the incorporation of metal species on zeolite supports as shown in the following sections.

\subsection{Bottom-Up Approach}

The synthesis of hierarchical zeolites via the bottom-up approach is illustrated using any organic templates to control the hierarchical structure. Among various types of zeolites, the ZSM-5 is one of the most popular types, having been applied in various catalytic applications due to the appropriate porous structure consisting of the intersected cavities between straight and zigzag channels, which are built from pentasil units. Recently, hierarchical ZSM-5 nanosheets with various $\mathrm{Si} / \mathrm{Al}$ ratios were successfully synthesized by a simple hydrothermal method using tetrabutylphosphonium hydroxide (TBPOH) as a bifunctional template [22]. The TBPOH can act as a dual template as a structure-directing agent of MFI (Mobil-type five) porous structure and a template of hierarchical structures. Tetraethyl orthosilicate (TEOS) and aluminium isopropoxide were used as silica and alumina sources, respectively. Sodium hydroxide $(\mathrm{NaOH})$ was dissolved in deionized water used as a mineralizing agent. The amount of alumina source was varied to obtain the ZSM-5 nanosheets with different $\mathrm{Si} / \mathrm{Al}$ ratios. The mixed precursors were stirred at ambient temperature to get a homogeneous solution. The crystallization process was finally hydrothermally performed to obtain the hierarchical ZSM-5 with uniform nanosheet morphology.

Subsequently, the ZSM-5 nanosheet with hierarchically nanospherical structure and homogenous Al distribution in the MFI framework was efficiently established using nanobeads of aluminosilicate (AS) as silicon and aluminium sources [23]. The homogeneous distribution of $\mathrm{Al}$ sites in $\mathrm{AS}$ beads can enhance the dispersion of $\mathrm{Al}$ sites in the structure of the established 
ZSM-5 nanosheets. The proposed mechanism of nanospherical ZSM-5 nanosheet formation using AS nanobeads compared to using a conventional precursor is shown in Figure 1. First, the silica and alumina sources were dissolved in basic solution, and tetrabutylammonium hydroxide $(\mathrm{TBAOH})$ was used as an organic template. After aging and crystallization, the synthesized hierarchical ZSM- 5 using AS beads as precursors showed the high dispersion of $\mathrm{Al}$ sites in the zeolite framework, while the use of separated $\mathrm{Al}$ and $\mathrm{Si}$ sources provided non-homogenous $\mathrm{Al}$ distribution over the prepared ZSM-5 nanosheet surfaces.

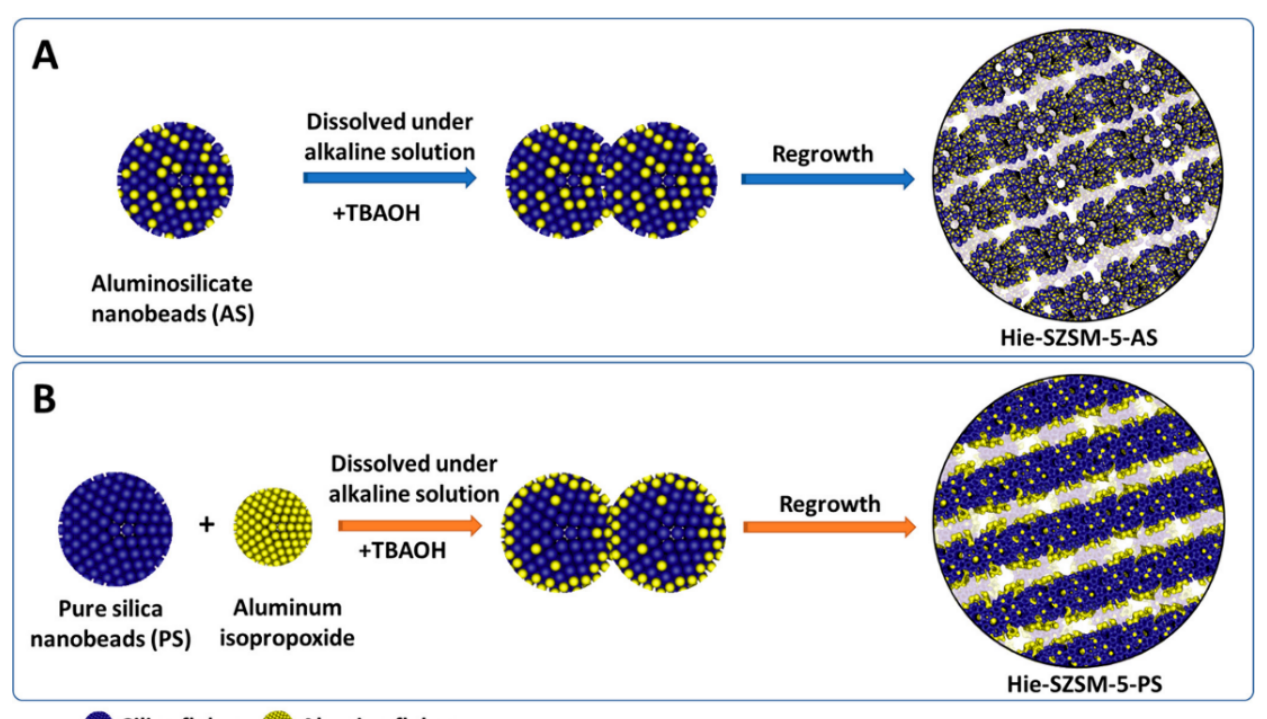

Silica flakes

Alumina flakes

Figure 1. Proposed formation procedure of the ZSM-5 nanosheets with hierarchically nanospherical structure using different starting silica and alumina precursors: (A) aluminosilicate nanobeads (AS) and (B) pure silica nanobeads (PS) and aluminum isopropoxide as silica-alumina sources. Reprinted with permission from [23]. Copyright 2020 American Chemical Society.

Apart from hierarchical ZSM-5 nanosheets, mesoporous ZSM-5 zeolites were efficiently created by using various types of mesoporous templates. Dimethyl octadecyl [3-(trimethoxysilyl)propyl] ammonium chloride (TPOAC) and hexadecyl trimethyl ammonium bromide (CTAB) were used as mesoporogens combining with tetrapropyl ammonium bromide (TPABr) used as a structure-directing agent (SDA) of ZSM-5 zeolites [24]. Colloidal silica (Ludox) and sodium aluminate $\left(\mathrm{NaAlO}_{2}\right)$ were used as silica and alumina precursors, respectively. Moreover, sodium hydroxide aqueous solution and concentrated sulfuric acid were added into the synthetic gel to be a mineralizing agent and to adjust the $\mathrm{pH}$ to be neutral, respectively. The mixed solution was stirred and hydrothermally treated to obtain the crystalline mesoporous ZSM-5. In addition, the uniform mesoporous ZSM-5,

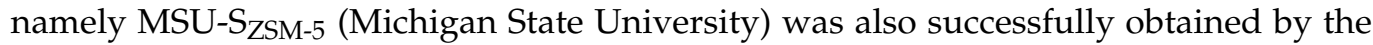
above-mentioned similar procedure [13]. Tetrapropyl ammonium hydroxide (TPAOH) used as a SDA of MFI was mixed with DI water, fumed silica, and $\mathrm{NaAlO}_{2}$. After that, the mixed solution was stirred to form the ZSM-5 zeolite seed in the solution. The CTAB aqueous solution was added into the prepared seed solution. The final synthetic gel was hydrothermally treated in a Teflon-lined autoclave to form the hierarchically mesoporous MSU-S ZSM-5.

Furthermore, the carbon black can be used as a hard template to synthesize the hierarchical structure of ZSM-5 zeolite [25]. The amount of carbon black was equal to the amount of added silica source by weight (100 wt.\%). The synthetic gel contains sodium chloride $(\mathrm{NaCl})$, aluminium isopropoxide, TPAOH solution, TEOS, and carbon black template. Before the crystallization step, the resulting mixture was evaporated to remove the excess solvent and to form the desired gel composition. After that, the resultant gel was hydrothermally treated, eventually producing the hierarchical ZSM-5 zeolite product. 
Moreover, the ultrathin ZSM-5 zeolite with two-dimensional sheet-like morphology was successfully synthesized by using a quaternary ammonium surfactant of $\mathrm{C}_{8} \mathrm{H}_{17}-\mathrm{N}^{+}\left(\mathrm{CH}_{3}\right)_{2}-$ $\mathrm{C}_{6} \mathrm{H}_{12}-\mathrm{N}^{+}\left(\mathrm{CH}_{3}\right)_{2}-\mathrm{C}_{8} \mathrm{H}_{17}$ as an SDA [25]. Aluminium sulfate octadecahydrate and LUDOX were used as alumina and silica precursors, respectively. The synthetic mixture was crystallized under stirring conditions to obtain the ultrathin ZSM-5 product. In addition, the hierarchical nanosized ZSM-5 zeolite was generated using the dry gel method and hexadecyltrimethoxysilane (HTS) as a mesoporogen [26]. TEOS, HTS, aluminum tritertbutoxide (ATTB), and TPAOH were dissolved in ethanol. The synthetic solution was stirred to obtain the homogenous gel before the solvent evaporation process. The resulting gel was transferred to a Teflon cup surrounded with water to create the steam-assisted hydrothermal condition. The hydrothermal crystallization step was finally performed to form the hierarchically mesoporous ZSM-5.

Apart from the hierarchical ZSM-5 zeolites, the hierarchical beta (BEA) zeolites have been also successfully generated by the bottom-up method. The BEA zeolite is composed of an intergrowth between two distinct polymorphs, which are the three-dimensional network of 12-membered ring pores. Because the BEA zeolite has large pore size, it is popular for the catalytic conversion of large molecules such as glucose conversion to hydroxymethylfurfural (HMF) [27]. The nanosized BEA zeolite was synthesized by using the normal hydrothermal procedure [28]. Tetraethylammonium hydroxide (TEAOH) was used as a SDA of BEA zeolite. Aluminum isopropoxide and silica powder from colloidal silica were used as alumina and silica sources, respectively. The synthetic solution was hydrothermally heated in a polypropylene bottle to crystallize the BEA nanoparticles. Additionally, the hierarchical BEA zeolite with nano-sponge morphology was efficiently synthesized by using a poly-quaternary ammonium surfactant as an organic template [28]. The synthetic gel contains ethanol, $\mathrm{NaOH}$, sodium aluminate, TEOS, and the surfactant. The resultant mixture was aged and then hydrothermally heated under the tumbling condition. After that, the crystallized solid product was washed, dried, and calcined to get the nano-sponge BEA zeolite. In addition, the CHA zeolite is an interesting small pore zeolite consisting of a three-dimensional porous structure with the cages of 8-membered rings. It has been applied in many catalytic reactions such as the alcohol conversion to light olefins [29] and the selective catalytic reduction (SCR) of $\mathrm{NO}_{x}$ by ammonia [30]. For the faujasite (FAU) zeolite, it is composed of very large cages (supercages) of 12-membered rings, and the reactions commonly occur in these supercages, so it has been used in the catalytic reactions of large molecules such as the benzylation of toluene [31]. Interestingly, the CHA zeolite nanoparticles have been successfully synthesized using the hydrothermal transformation of FAU zeolite and $\mathrm{N}, \mathrm{N}, \mathrm{N}$-trimethyl-1-adamantammonium hydroxide (TMAdaOH) as an organic structure-directing agent (OSDA) [32]. The dealuminated FAU powder was mixed with an aqueous solution of $\mathrm{NaOH}, \mathrm{TMAdaOH}$, and calcined $\mathrm{CHA}$ seed crystals. The resulting solution was transferred to a Teflon-lined stainless-steel autoclave and hydrothermally treated to convert the FAU zeolite to the nanosized CHA zeolites.

From the above-mentioned literature according to zeolite synthesis via the bottomup approach, the different structure-directing agent (SDA) offers the different role in the synthetic process. For example, the TBPOH acts simultaneously as the SDA of MFI zeolite framework and the nanosheet template by controlling the limited MFI zeolite growth in the two-dimensional structures [33]. In contrast, the TPOAC and the CTAB act as mesoporogens so that the SDA of each zeolite framework is required in the synthetic procedure, such as TPABr and TPAOH for the ZSM-5 zeolite and TEAOH for the BEA zeolite.

\subsection{Top-Down Approach}

The top-down approach is the post-synthetic treatment of zeolites to create the additional mesopores and/or macropores in the zeolite crystals. There are two main methods, desilication and dealumination, in which the removal of $\mathrm{Si}$ and $\mathrm{Al}$ from the zeolite frameworks was obtained, respectively. For example, the desilication of ZSM-5 zeolite was 
performed by mixing the $\mathrm{NaOH}$ solution with the parent ZSM- 5 under vigorous stirring at $65{ }^{\circ} \mathrm{C}$ in a polypropylene bottle [34]. Dealumination has been achieved by an acid treatment. The oxalic acid aqueous solution was used to dealuminate the ZSM-5 zeolite [35]. However, the aluminum located on external surfaces of zeolite crystals is dissolved because the three moles of oxalic acid can form a chelate with a mole of aluminum. Therefore, the other post-synthetic treatments are applied to generate additional mesopores and/or macropores. For example, the sequential desilication and dealumination was successfully done by using $\mathrm{NaOH}$ and oxalic acid solutions using the above-mentioned procedures [36]. Subsequently, the sequence of post-synthetic treatments over zeolite L was studied with various desilication and dealumination approaches as shown in Figure 2 [37]. The first route (I) is the desilication with $\mathrm{NaOH}$ solution followed by dealumination with the $\mathrm{HNO}_{3}$ solution to remove the extra-framework aluminum species generated from the previous desilication. For the second approach (II), the acid treatment of zeolite $\mathrm{L}$ with $\mathrm{HNO}_{3}$ solution was first performed. Subsequently, the dealuminated zeolite $\mathrm{L}$ was treated with $\mathrm{NaOH}$ for the desilication. The third procedure (III) was done by the dealumination under mild conditions with $\mathrm{NH}_{4} \mathrm{Cl}$ solution and subsequent alkaline treatment with $\mathrm{NaOH}$ solution. This procedure provided a better $\mathrm{pH}$ control and simultaneous $\mathrm{NH}_{4}{ }^{+}$ion-exchange with alkaline ions in the zeolite framework for the dealumination step. For the last approach (IV), the dealumination was performed via steaming with continuous liquid water flow followed by the desilication with $\mathrm{NaOH}$ solution. Moreover, the post-synthetic treatment with steaming was also studied for creating the hierarchical ZSM-5 zeolite [38]. This steam treatment was performed in a fixed-bed flow reactor at various temperatures ranging from 400 to $550{ }^{\circ} \mathrm{C}$.

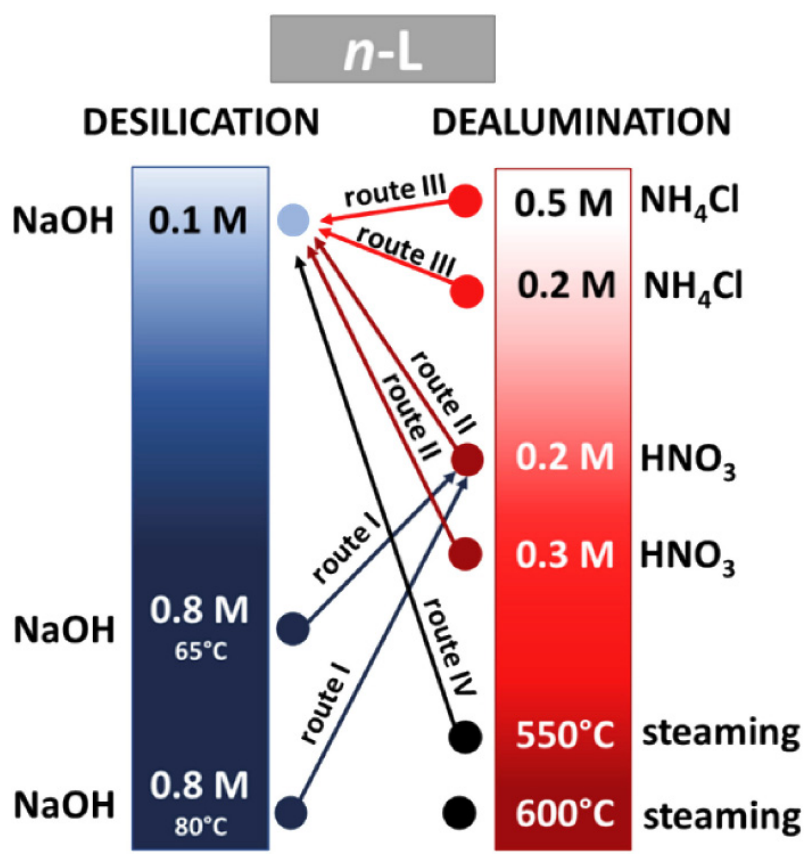

Figure 2. Various sequent post-synthetic treatment procedures of zeolite L. Reprinted with permission from [37]. Copyright 2017 Elsevier Inc.

Furthermore, the organic templates were also used for the alkaline treatments of zeolites. The microporous ZSM- 5 was desilicated using tetrabutylammonium hydroxide (TBAOH) and $\mathrm{NaOH}$ mixture solution to obtain the hierarchical ZSM-5 [25]. In addition, ultrasound was used in the desilication process to extract silicon from the zeolite framework, eventually providing higher mesoporosity compared to the method without ultrasound [39]. The ultrasonic-assisted desilication of MFI-type zeolite was carried out at low temperature using the mixed solution of $\mathrm{NaOH}$ and $\mathrm{TBAOH}$ under ultrasound conditions generated by the QSonica Q700 sonicator. In addition, the mesoporous BEA zeolite 
was desilicated using various alkaline sources such as $\mathrm{NaOH}$, tetrapropylammonium hydroxide (TPAOH), and tetramethylammonium hydroxide (TMAOH) [40]. The conditions of desilication were varied by using different treatment times, temperatures, and concentrations of alkaline solutions to optimize the treatment condition. Recently, the intracrystalline mesoporosity was created in the BEA zeolite via a surfactant-template strategy [41]. The quaternary ammonium surfactants with various alkyl chain lengths $\left(C_{10}\right.$ to $\left.C_{16}\right)$ including decyltrimethylammonium bromide (DTAB-10), tetradecyltrimethylammonium bromide (TTAB), dodecyltrimethylammonium bromide (DTAB-12), and cetyltrimethylammonium bromide (CTAB) were used to construct the intracrystalline mesoporous BEA zeolites with adjustable pore size (1.9-3.4 $\mathrm{nm}$ ) controlled by the length of surfactant alkyl chain $\left(\mathrm{C}_{10}\right.$ to $\left.\mathrm{C}_{16}\right)$. For the experiment, the BEA zeolite was mixed with the solution of $\mathrm{NaOH}$ and a surfactant. Subsequently, the resulting solution was hydrothermally heated in a stainless-steel Teflon-lined autoclave to obtain the hierarchically mesoporous BEA zeolite. Interestingly, it was found that the $\mathrm{CTA}^{+}$is the key factor for the construction of mesoporosity and can inhibit the destruction of the zeolite framework and create the separated mesoporous phase.

Apart from the above-mentioned desilication and dealumination, post-synthetic treatments of zeolites via the fluoride media have been proposed [42,43]. In 2016, the controllable dissolution of zeolite framework fragments by fluoride treatment was reported [44]. The ammonium fluoride $\left(\mathrm{NH}_{4} \mathrm{~F}\right)$ aqueous solution can generate various fluoride species with an equilibrium condition. For example, $\mathrm{HF}_{2}{ }^{-}$species can dissolve both $\mathrm{Si}$ and $\mathrm{Al}$ in the zeolite framework at an equal rate. Moreover, the $\mathrm{NH}_{4} \mathrm{~F}$ aqueous solution can also generate equilibrated $\mathrm{HF}$ and $\mathrm{NH}_{3}$ in the solution, and therefore it can moderate the etching condition to be mild and controllable. The hierarchical ZSM-5 zeolite with mosaic mesoporous structure was successfully prepared by $\mathrm{NH}_{4} \mathrm{~F}$ etching [44]. The pristine ZSM- 5 zeolite was dispersed in the $\mathrm{NH}_{4} \mathrm{~F}$ aqueous solution at $50{ }^{\circ} \mathrm{C}$ under stirring ultrasonication. In addition, the intermediate samples were taken out at various reaction times to study the mechanism related to the fluoride etching. The proposed mechanism is shown in Figure 3 [44]. For the zeolite crystallization process (Figure 3A), the starting $\mathrm{Si}$ and $\mathrm{Al}$ were crystallized to be nanoparticles and then these nanocrystals were grown to be completed crystalline crystals. For the zeolite dissolution with the $\mathrm{NH}_{4} \mathrm{~F}$ treatment (Figure 3B), the defect zone of zeolite crystals, which is the interface between nanocrystals or grain boundaries, was dissolved first and then the internal part of the nanocrystals was also dissolved by the fluoride solution. Consequently, the mesopores of zeolite can be built with the mosaic structure. In addition, the hierarchical ZSM-5 zeolite with a houseof-cards like porous structure was successfully synthesized using the above-mentioned procedure [45]. The mordenite (MOR) zeolite is composed of 8- and 12-membered ring channels without the intersection between these two units. It has been applied in many catalytic reactions such as the partial oxidation of methane to methanol [46], dimethyl ether carbonylation [47], and esterification with oleic acid [48]. Recently, the pore-opened mordenite (MOR) zeolite was also efficiently prepared using the similar $\mathrm{NH}_{4} \mathrm{~F}$ etching method [49]. The parent MOR zeolite was treated with the $\mathrm{NH}_{4} \mathrm{~F}$ aqueous solution to create the mesoporous network over the MOR crystals. Remarkably, the $\mathrm{NH}_{4} \mathrm{~F}$ etching process not only creates mesoporosity but also generates the preserved framework composition ( $\mathrm{Si}$ and $\mathrm{Al}$ content) and crystallinity of the parent zeolite.

In addition, the treatment with alkali salts was successfully applied as shown in various studies. For example, the chromosilicate ZSM-5 type zeolite was synthesized using the simple hydrothermal method with the addition of sodium $(\mathrm{Na})$, potassium $(\mathrm{K})$, or cesium (Cs) carbonate as alkali salts in the synthetic gel [50]. Interestingly, the use of different alkaline sources provides distinct catalyst properties such as the zeolite crystallinity, which is in the order of $\mathrm{Na}>\mathrm{K}>\mathrm{Cs}$. Subsequently, the acid ZSM- 5 zeolite was modified with $\mathrm{LiNO}_{3}, \mathrm{NaNO}_{3}, \mathrm{KNO}_{3}$, and $\mathrm{CsNO}_{3}$ by an ion-exchange method to study the effect of alkali metal cations on the acidic properties of a catalyst [51]. It was found that the treatment of ZSM-5 zeolite with these alkali sources resulted in a decrease 
in strong Brønsted acid sites and an increase in Lewis acid densities. Furthermore, the Cs-ZSM-5 zeolite catalysts with different Cs loading were successfully prepared using a wet impregnation method with cesium nitrate $\left(\mathrm{CsNO}_{3}\right)$ solution [52]. The results showed that the Si species are partially dissolved from the ZSM-5 zeolite structure after the $\mathrm{CsNO}_{3}$ impregnation, and the amount of $\mathrm{CsNO}_{3}$ basic sites affects the deactivation of catalyst.

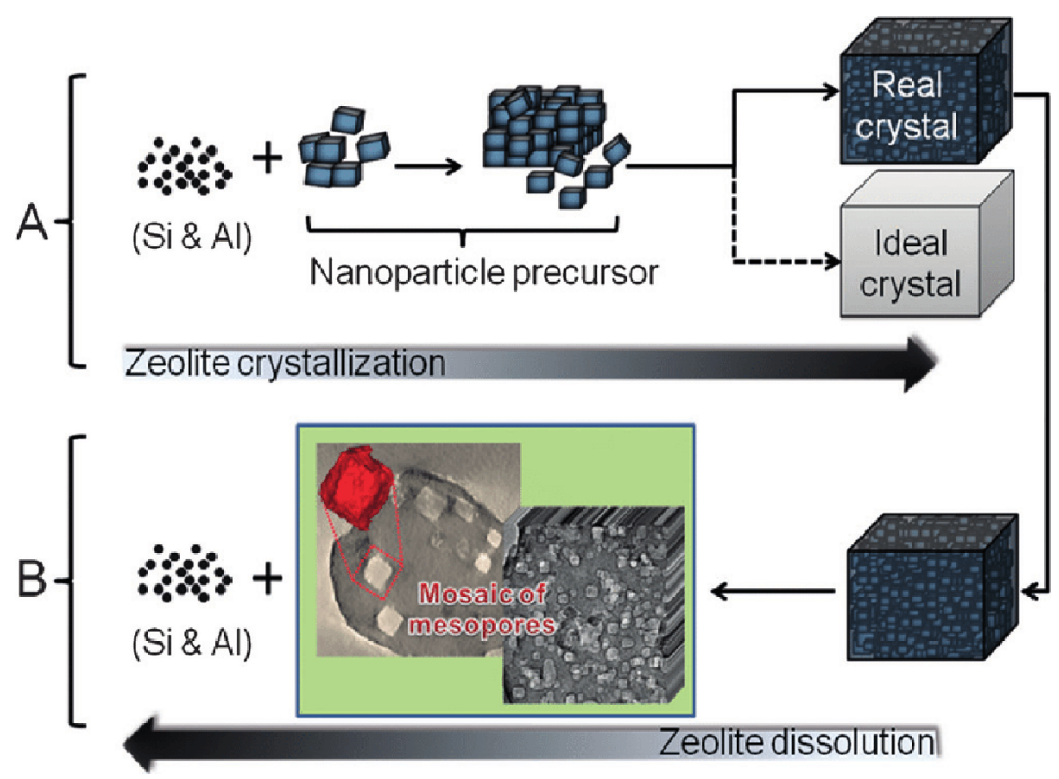

Figure 3. Proposed mechanisms of crystalline zeolite growth (A) and dissolution of zeolite crystals via the $\mathrm{NH}_{4} \mathrm{~F}$ etching (B). Reprinted with permission from [44]. Copyright 2016 Wiley-VCH Verlag $\mathrm{GmbH} \& \mathrm{Co}$. KGaA, Weinheim.

\subsection{Incorporation of Metal Species into Zeolite Supports}

Incorporation of metal species into zeolites is an important task because the metal species can be an active site and adjust the acid-base properties of zeolite catalysts. Typically, there are two conventional methods for adding metals to zeolite supports, which are ionexchange and impregnation strategies. Recently, the cerium metal was loaded on the hierarchical MFI zeolite via these two methods [53]. For the ion-exchange strategy, the MFI zeolite was mixed and stirred with an aqueous solution of cerium (III) acetate. Subsequently, the suspension was filtered, cleaned with DI water, and dried. For the impregnation method, the mixture suspension of hierarchical MFI and cerium (III) acetate solution was stirred for a long time to get the homogenous suspension. After that, the rotary evaporator was used to remove the solvent and the solid product was dried. Finally, ceria incorporated hierarchical MFI zeolites prepared by both methods were obtained after the calcination. Moreover, the tungsten oxide was also successfully loaded on the MFI zeolite nanosheets by an incipient wetness impregnation (IWI) method [54]. In the experimental details, the ammonium metatungstate hydrate solution was used as a metal source. Furthermore, other metals, such as vanadium (V), lanthanum (La), and titanium (Ti) were incorporated in ZSM-5 and ferrierite (FER) using the IWI approach [55]. Different chemical sources and solvents were used for the preparation of different types of loaded metals on zeolites. For the vanadium $(\mathrm{V})$, the ammonium vanadate $\left(\mathrm{NH}_{4} \mathrm{VO}_{3}\right)$ and hydrogen peroxide $\left(\mathrm{H}_{2} \mathrm{O}_{2}\right)$ were applied as a chemical precursor and a solvent, respectively. In the case of lanthanum $(\mathrm{La})$, the zeolites were treated with a lanthanum nitrate hexahydrate $\left(\mathrm{La}\left(\mathrm{NO}_{3}\right)_{3} \cdot 6 \mathrm{H}_{2} \mathrm{O}\right)$ aqueous solution. The titanium (Ti) loaded on a zeolite support was prepared using the solution of titanium isopropoxide dissolved in isopropanol. Interestingly, nickel (Ni) was also impregnated in zeolites using various strategies. The $5 \mathrm{wt}$ \% of $\mathrm{Ni}$ was incorporated in the ZSM-5 zeolite using a nickel(II) nitrate hexahydrate aqueous solution via the wet incipient method [56]. In the another procedure, the $1 \mathrm{wt} \%$ of Ni loaded on ZSM-5 zeolite 
was prepared by slow dropping of $\mathrm{Ni}\left(\mathrm{NO}_{3}\right)_{2} \cdot 6 \mathrm{H}_{2} \mathrm{O}$ solution on the ZSM-5 powder [57]. The Ni metal was loaded on the BEA zeolite by a sol gel impregnation method [58]. The precursor solution was prepared by mixing $\mathrm{Ni}\left(\mathrm{NO}_{3}\right)_{3} \cdot 6 \mathrm{H}_{2} \mathrm{O}$ and citric acid in deionized water with an equal molar ratio. The mixture solution was stirred to get a transparent solution with a green color. Subsequently, the resulting solution was gradually added into the BEA zeolite and further treated to acquire the transparent and green jelly. Finally, the $\mathrm{Ni}$ incorporated BEA zeolites with 5-15 wt.\% of Ni loading were obtained after calcination. In addition, cobalt ( $\mathrm{Co}$ ) was supported on the super dealuminated ultrastabilized Y zeolite (USY) [59] and the mesoporous Y zeolite [60] by the IWI method using a cobalt(II) nitrate aqueous solution.

Zeolites can be incorporated with various combined metal species. For example, vanadium (V) and indium (In) were successfully loaded on the ZSM-5 zeolite as a bimetallic InV-ZSM-5 catalyst [61]. In the experimental detail, the V-ZSM-5 was firstly prepared using vanadium(III) chloride as a metal source. The ZSM- 5 zeolite was mixed with a $\mathrm{VCl}_{3}$ aqueous solution followed by reflux to obtain the V-ZSM- 5 product with a light blue color. After that, the color of V-ZSM-5 catalyst was changed to be light yellow by calcination. Subsequently, the obtained V-ZSM-5 zeolite was ion-exchanged with indium(III) nitrate aqueous solution under reflux conditions. Finally, the resulting suspension was filtered, washed, dried, and calcined to obtain the bimetallic InV-ZSM-5 catalyst. In addition, the molybdenum (Mo) and zinc $(\mathrm{Zn})$ were supported on the aluminophosphate zeolite with the AFI framework structure $\left(\mathrm{AlPO}_{4}-5\right)$ using a co-impregnation strategy with various molar ratios of Mo/Zn [62]. The metal precursors are ammonium molybdate and zinc acetate. In addition, the silver (Ag)-promoted zirconium (Zr)-BEA zeolite was prepared by the following procedure [63]. The BEA zeolite was pretreated before the incorporation of zirconium. The pretreated BEA zeolite was mixed with $\mathrm{ZrOCl}_{2} \cdot 8 \mathrm{H}_{2} \mathrm{O}$ solution in DMSO solvent under heating conditions. DI water was then added into the solution. The suspension was then filtered, washed with water, dried, and calcined to obtain the Zr-BEA zeolite. Subsequently, a $1 \mathrm{wt} . \%$ of silver $(\mathrm{Ag})$ was doped into the prepared $\mathrm{Zr}$-BEA zeolite by the impregnation method using an $\mathrm{AgNO}_{3}$ solution. The Ag-promoted $\mathrm{Zr}$-BEA zeolite was finally obtained after calcination and reduction with hydrogen. Furthermore, the magnesium $\left(\mathrm{Mg}\right.$ ) was also incorporated in the $\mathrm{Zr}$-zeolite [64]. The $\mathrm{ZrO}_{\mathrm{x}} / \mathrm{MFI}$ nanosheet zeolite was first prepared by the impregnation with zirconium oxynitrate aqueous solution. Subsequently, the magnesium $(\mathrm{Mg})$ was impregnated into the prepared $\mathrm{ZrO}_{\mathrm{x}} /$ zeolite nanosheet using a magnesium nitrate solution to obtain the $\mathrm{Mg}-\mathrm{ZrO} \mathrm{O}_{\mathrm{x}} / \mathrm{MFI}$ nanosheet catalyst. The tantalum (Ta)-containing Si-rich BEA zeolite (TaSiBEA) was doped with various metal types including silver $(\mathrm{Ag})$, copper $(\mathrm{Cu})$, and zinc $(\mathrm{Zn})$ [65]. The solution of $\mathrm{Ta}\left(\mathrm{OC}_{2} \mathrm{H}_{5}\right)_{5}$ in isopropanol was used for the incorporation of tantalum (Ta) in the SiBEA zeolite. The mixture of zeolite and Ta solution was stirred and then the solvent was evaporated under vacuum conditions. After that, the solid product was washed with distilled water three times, dried, and calcined under air flow, eventually producing the white TaSiBEA sample. Subsequently, the obtained TaSiBEA zeolite was doped with various metal precursors including $\mathrm{Zn}\left(\mathrm{NO}_{3}\right)_{2} \cdot 6 \mathrm{H}_{2} \mathrm{O}, \mathrm{Cu}\left(\mathrm{NO}_{3}\right)_{2} \cdot 3 \mathrm{H}_{2} \mathrm{O}$, and $\mathrm{AgNO}_{3}$ aqueous solutions to obtain the $\mathrm{Zn}, \mathrm{Cu}$, and Ag-incorporated TaSiBEA zeolites, respectively. Remarkably, the three different metal species can be loaded on a zeolite support. The MFI nanosheet zeolite was incorporated with lithium $(\mathrm{Li})$, zinc $(\mathrm{Zn})$, and hafnium $(\mathrm{Hf})$ metals by the wet impregnation method [15]. The solutions of $\mathrm{Li}_{2} \mathrm{CO}_{3}, \mathrm{Zn}\left(\mathrm{NO}_{3}\right)_{2} \cdot 6 \mathrm{H}_{2} \mathrm{O}$, and $\mathrm{HfCl}_{4}$ were used as metal sources to successfully prepare the LiZnHf-MFI nanosheet zeolite.

In addition, the bimetallic Fe-Mo and trimetallic Cs-Fe-Mo/ZSM-5 zeolite catalysts were prepared by the two- and three-step impregnation processes, respectively [66]. In the first step, the ZSM- 5 zeolite was treated with an aqueous solution of $\left(\mathrm{NH}_{4}\right)_{6} \mathrm{Mo}_{7} \mathrm{O}_{24} \cdot 4 \mathrm{H}_{2} \mathrm{O}$ under stirring. Subsequently, a solution of $\mathrm{Fe}\left(\mathrm{NO}_{3}\right)_{3} \cdot 9 \mathrm{H}_{2} \mathrm{O}$ was introduced into the previous suspension. The final step was the impregnation with a $\mathrm{CsNO}_{3}$ solution. After the drying and calcination of the zeolite product, the trimetallic Cs-Fe-Mo/ZSM- 5 catalyst was obtained. Recently, the trimetallic Zn-promoted $\mathrm{Cu}-\mathrm{Ni}$ alloy supported on ZSM-5 zeolite 
catalyst was successfully generated by the one-step impregnation method [67]. The mixed solution of all metal precursors was prepared and used to simultaneously impregnate the $\mathrm{Zn}, \mathrm{Cu}$, and Ni metal species on the ZSM-5 zeolite. Moreover, the bimetallic V-Cu/ZSM-5 zeolite catalyst was also successfully synthesized by the impregnation method using the ammonium metavanadate $\left(\mathrm{NH}_{4} \mathrm{VO}_{3}\right)$ and copper nitrate hydrate $\left(\mathrm{Cu}\left(\mathrm{NO}_{3}\right)_{2} \cdot \mathrm{xH}_{2} \mathrm{O}\right)$ as metal precursors [68].

Apart from the incorporation of metals into zeolites via the post-synthetic modification methods, the one-pot synthesis of metal incorporated zeolite can be achieved. The Cu-SSZ-13 zeolite was successfully established by the one-pot method using $\mathrm{Cu}$ tetraethylenepentamine (Cu-TEPA) complex as a copper source [69]. For the experiment, $\mathrm{NaAlO}_{2}$ and $\mathrm{NaOH}$ were first dissolved in water. The $\mathrm{CuSO}_{4} \cdot 5 \mathrm{H}_{2} \mathrm{O}$ and TEPA were then added into the solution under stirring conditions. The mixture was further stirred and then the silica sol was added under vigorous stirring. The synthetic gel was further stirred, transferred into an autoclave, and hydrothermally heated to crystallize the zeolite product. Subsequently, the crystallized solid was washed with large amounts of water, dried, and calcined to obtain the Cu-SSZ-13 catalyst containing $12.9 \mathrm{wt} . \%$ of $\mathrm{Cu}$ content. Moreover, the isomorphous substitution of various metals into zeolite frameworks was another strategy for the preparation of metal incorporated zeolite catalysts via the one-pot synthesis [70]. In addition, the summary of the preparation perspectives of hierarchical zeolite catalysts is shown in Table S1.

\section{Characterization of Hierarchical Zeolite Catalysts}

Characterization is strongly required to investigate the properties of hierarchical zeolite catalysts, which can affect to the catalytic behaviors. Characterization can be classified into two main groups including: (i) textural properties and pore architecture; (ii) acidic properties and active species, as shown in detail below.

\subsection{Textural Properties and Pore Architecture}

Textural properties and pore architecture of hierarchical zeolite catalysts are normally investigated by the gas adsorption-desorption technique and transmission electron microscopy (TEM), respectively. For example, the desilicated ZSM-5 zeolites that have different $\mathrm{Si} / \mathrm{Al}$ ratios (20 and 50 ) were characterized with the $\mathrm{N}_{2}$-sorption technique to investigate the textural properties to compare the different aspects between the ones before and after the alkaline treatment [34]. The $\mathrm{N}_{2}$ sorption isotherms are shown in Figure 4. The type I isotherm was observed in the case of the parent ZSM-5 samples (HZSM-5_(S50) and HZSM-5_(S20)), indicating the zeolites with microporous structure. For the treated sample (HZSM-5_PT(S50)), it showed the characteristic of a type IV isotherm with a hysteresis loop, resulting from the capillary condensation of $\mathrm{N}_{2}$ in the mesopores of zeolite. It was found that the textural properties of the desilicated ZSM-5 zeolite with lower Si/Al ratio (HZSM5_PT(S20)) are not significantly different compared to the pristine one (HZSM-5_(S20)). In contrast, the surface area and volume of mesopores were significantly increased from 61 to $212 \mathrm{~m}^{2} / \mathrm{g}$ and 0.07 to $0.37 \mathrm{~cm}^{3} / \mathrm{g}$ after the alkaline treatment in the case of higher Si / Al ratio ZSM-5 zeolite. It should be noted that the HZSM-5_(S20) and HZSM-5_(S50) are the ones before the alkaline treatment, which have 20 and 50 of $\mathrm{Si} / \mathrm{Al}$ ratios, respectively. The abbreviation of PT in the HZSM-5_PT(S20) and HZSM-5_PT(S50) is the representative symbol of samples after the alkaline treatment.

In addition, the textural properties and porous structure of hierarchical MFI zeolite with nanosheet morphology were examined and compared to those of the microporous MFI zeolite [15]. The SEM and TEM images of MFI zeolite samples clearly illustrated the different morphology between microporous and hierarchical MFI zeolites. The microporous MFI showed bulk hexagonal crystal morphology with particle size of $500 \mathrm{~nm}$. The hierarchical MFI presented $200 \mathrm{~nm}$ of uniform spherically-shaped crystals with a rough surface of stacked nanosheets. The TEM image of MFI nanosheet zeolite displayed 2 to $10 \mathrm{~nm}$ of sheet thickness and intracrystalline mesopores between nanosheets. For the $\mathrm{N}_{2-}$ 
sorption results, the bulk and nanosheet MFI zeolites showed the type IV and I isotherms corresponding to the microporous and mesoporous structures, respectively. Remarkably, the hierarchical MFI nanosheet zeolite exhibited higher mesopore volume and external surface area compared to the bulk MFI sample. In addition, the textural properties of hierarchical ZSM- 5 zeolites synthesized by various procedures including desilication, $\mathrm{NH}_{4} \mathrm{~F}$ etching, and nanosheet templating approaches were investigated [45]. The desilicated ZSM-5 showed higher mesoporosity and lower micropore volume compared to the parent ZSM-5, indicating that although the desilication can create mesopores, it can also destroy the zeolite framework. The fluoride treated sample exhibited higher mesopore volume with the comparable volume of micropores with respect to the parent one, indicating that the $\mathrm{NH}_{4} \mathrm{~F}$ etching can construct the mesoporous structure and preserve the microporosity. The ZSM-5 nanosheet zeolite displayed the lowest micropore volume but the highest surface area and mesopore volume according to the crystal architecture of nanosheet stacking. For the distribution of pore size, while the major pore sizes of nanosheet and desilicated ZSM-5 zeolites were in the range of 2-50 nm, the $\mathrm{NH}_{4} \mathrm{~F}$ etched zeolite exhibited large pore size between $10 \mathrm{~nm}$ and more than $100 \mathrm{~nm}$. Moreover, it was found that although the three hierarchical ZSM-5 zeolites show similarly high mesopore volumes, the fluoride treated sample presents much lower external surface area than the others. This behavior can be explained by the different pore size distribution. In addition, from the equation of $\mathrm{d}=4 \mathrm{~V} / \mathrm{S}$ where $\mathrm{d}, \mathrm{V}$, and $\mathrm{S}$ parameters are the pore diameter, pore volume, and surface area, respectively, it means that if the zeolite has larger pore size, it will have lower surface area, which is the same case with the $\mathrm{NH}_{4} \mathrm{~F}$ etched zeolite sample.
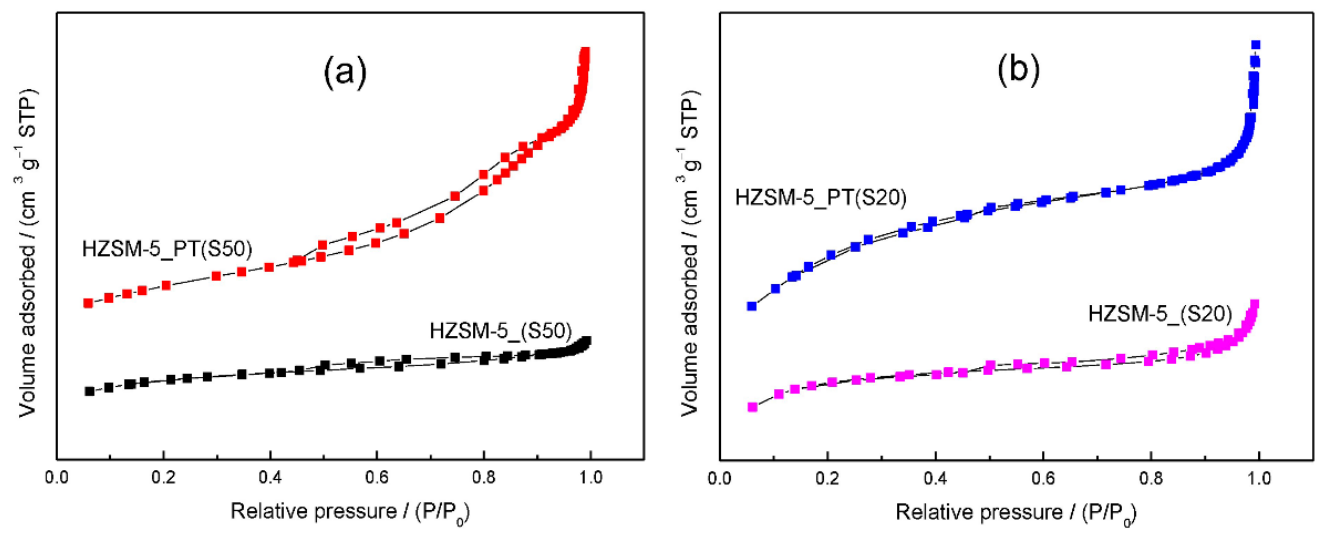

Figure 4. $\mathrm{N}_{2}$ sorption isotherms of the ZSM-5 zeolites before and after desilication with different $\mathrm{Si} / \mathrm{Al}$ ratios: (a) $\mathrm{Si} / \mathrm{Al}$ ratio of 50 and (b) Si/Al ratio of 20. Reprinted with permission from [34].

Recently, the hierarchical BEA zeolites prepared by the surfactant-templating strategy were characterized by the $\mathrm{N}_{2}$-physisorption technique to study the effects of different alkyl chain lengths of quaternary ammonium surfactants and treatment conditions [41]. The $\mathrm{BJH}$ pore size distribution indicates that the hierarchical BEA zeolite with larger mesopore size can be obtained by the treatment of BEA zeolite with the longer alkyl chain length as the surfactant. For the effects of treatment time and alkaline concentration, it was found that the increase of treatment time and alkaline concentration resulted in an increase of mesoporosity and a decrease of micropore volume, indicating damage of the zeolite framework from the severe treatment conditions. Interestingly, the sufficient alkalinity and the interaction between the parent zeolite and the alkaline source were the important factors for the successful synthesis of intracrystalline mesoporous BEA zeolite via the surfactant-templating method. In addition, the porous structure and textural properties of nano-sponge (NS), nano-crystalline (NC), and micron-sized (MC) BEA zeolites were investigated [28]. From the SEM and TEM images, the MC BEA zeolite showed the bulk bipyramidal morphology that is characteristic of BEA zeolites. The NC BEA sample displayed the random aggregation of nanocrystals, resulting in the creation of intercrystalline 
mesopores. The NS BEA zeolite illustrated a sponge-like morphology with ordered mesopores. Moreover, the $\mathrm{N}_{2}$-sorption results revealed that the $\mathrm{MC}$ sample presents the type I isotherm and low external surface area $\left(33 \mathrm{~m}^{2} / \mathrm{g}\right)$ corresponding to the microporous characteristic. The NC zeolite displayed high mesopore volume $\left(0.71 \mathrm{~cm}^{3} / \mathrm{g}\right)$ and large external surface area $\left(223 \mathrm{~m}^{2} / \mathrm{g}\right)$ with $15-40 \mathrm{~nm}$ of the BJH pore size distribution. The NS BEA exhibited the type IV isotherm with pore network connectivity and narrow pore size distribution with $4 \mathrm{~nm}$ of center. It indicates that the hierarchical BEA zeolite with nanosponge morphology illustrated more ordered mesoporous structure than the nanocrystal BEA sample. Additionally, the effect of metal incorporation in the zeolite supports on the textural properties of catalysts can be also studied by the $\mathrm{N}_{2}$-physisorption technique. For instance, the pure silica MFI zeolite nanosheets before and after the incorporation of tungsten oxide $\left(\mathrm{WO}_{\mathrm{x}}\right)$ nanoparticle were examined in term of the textural properties by the above-mentioned technique [54]. The $\mathrm{WO}_{\mathrm{x}}$ loading was varied as $1,2,4$, and $6 \mathrm{~mol} \%$. It was found that all catalysts show the type IV isotherms according to the hierarchical nanosheet structures. Notably, the pore volume and surface area decreased with an increase of $\mathrm{WO}_{\mathrm{x}}$ content.

Apart from the characterization of textural properties by the $\mathrm{N}_{2}$-sorption technique, the quasi-equilibrated temperature programmed desorption and adsorption (QE-TPDA) method can be also used for the porosity evaluation. The QE-TPDA of volatile hydrocarbons was suitable for the investigation of micro- and mesoporosity [71]. The QE-TPDA profile was composed of the desorption and adsorption curves that are observed during heating and cooling the sample, respectively. In addition, the QE-TPDA of various hydrocarbons was employed to study the porosities of microporous ZSM-5 zeolite, desilicated ZSM-5, mesoporous ZSM-5 synthesized using amphiphilic organosilanes, carbon-black templated ZSM-5, and ultrathin ZSM-5 [25]. The QE-TPDA profiles of $n$-hexane showed the characteristics of two step desorption and adsorption patterns of ZSM- 5 zeolites. However, the additional desorption peak at low temperature and low intensity were observed in the case of desilicated and mesoporous ZSM-5 zeolites, indicating an increase in mesopore or external surface area [72]. The QE-TPDA profiles of cyclohexane displayed the single desorption peak corresponding to the molecules located in the intersection channels of the MFI pore structure. For the QE-TPDA of $n$-nonane, it illustrated low and high temperature features which are related to the desorption and adsorption at mesopores and micropores, respectively. Interestingly, the intensities of low temperature desorption of the mesoporous, ultrathin, and desilicated ZSM-5 zeolites were higher than those of the microporous and carbon-black templated zeolites. This may indicate that the mesoporous, ultrathin, and desilicated ZSM-5 samples present higher mesoporosity and/or external surface area than the microporous and carbon-black templated ZSM- 5 samples. Moreover, the mesoporous ZSM-5 zeolite showed the highest desorption temperature indicating the smallest mesoporous size. Furthermore, the pore volumes can be determined by the integration of the desorption QE-TPDA peaks. The microporous and carbon-black templated ZSM-5 samples displayed the highest micropore volume indicating that these ZSM-5 zeolites mainly consist of the MFI framework. In contrast, the lowest micropore volumes were found in the mesoporous and desilicated ZSM-5 zeolites, suggesting damage of the zeolite framework. In addition, the desilicated, mesoporous, and ultrathin ZSM-5 zeolites illustrated the high mesopore volume, which is consistent with their $\mathrm{N}_{2}$-adsorption-desorption results.

Recently, the visualization of zeolite pore architecture in three-dimensional views by electron tomography (ET) was revealed [49]. The MOR zeolites before and after the $\mathrm{NH}_{4} \mathrm{~F}$ etching were characterized by the ET technique with the tilting angles from $-70^{\circ}$ to $+70^{\circ}$ as shown in Figure 5. Promisingly, the fluoride treated MOR zeolite clearly illustrated the opened-porous structure with the pore network connectivity from the external surface into the internal zeolite crystal. In contrast, the parent MOR sample exhibited a small amount of closed mesopores inside the zeolite crystal. 

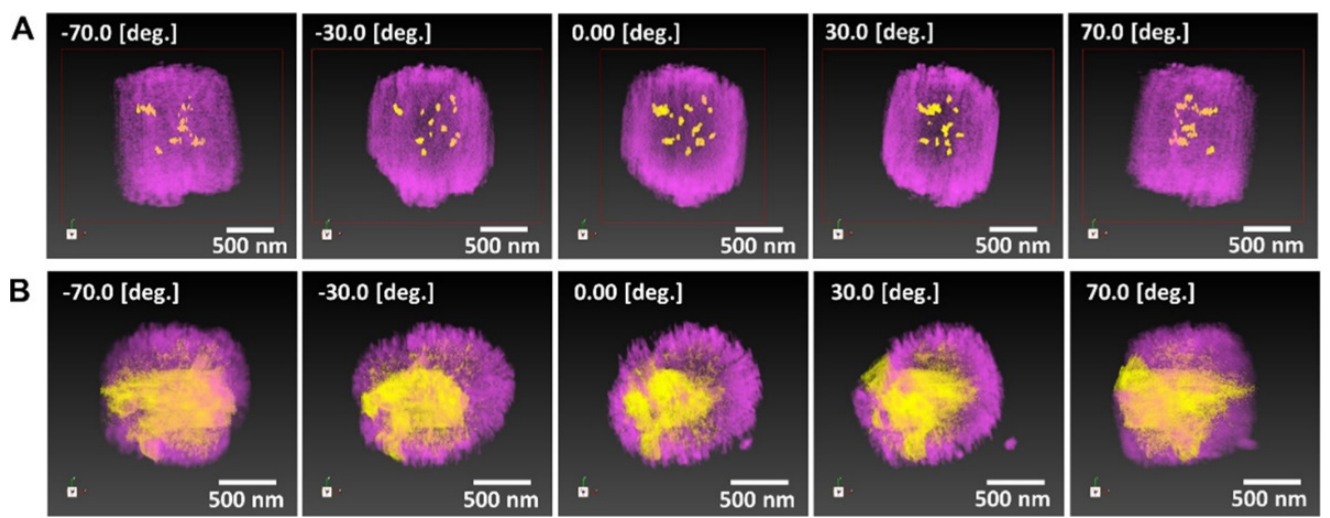

Figure 5. Three-dimensional pore visualization via the electron tomography with the tilting angles from $-70^{\circ}$ to $+70^{\circ}$ of the MOR zeolites before $(\mathbf{A})$ and after $(\mathbf{B})$ the $\mathrm{NH}_{4} \mathrm{~F}$ treatment. Reprinted with permission from [49]. Copyright 2021 American Chemical Society.

\subsection{Acid-Base Properties and Active Species}

Acid-base properties and active species are important characteristics of hierarchical zeolite catalysts and relate to their catalytic behaviors. The acidity of zeolite catalysts is normally examined by temperature programmed desorption of ammonia ( $\left.\mathrm{NH}_{3}-\mathrm{TPD}\right)$. The desorption temperature of $\mathrm{NH}_{3}$ can indicate the strength of acid sites. Moreover, the amount of acid sites can be also examined by $\mathrm{NH}_{3}$-TPD analysis based on the amount of desorbed ammonia. In addition, the acidic properties of zeolite $\mathrm{Y}$ catalysts before and after the acid modification with phosphoric acid were studied with $\mathrm{NH}_{3}$-TPD profiles [73]. The $\mathrm{NH}_{3}$-TPD profiles of the parent $\mathrm{Y}$ zeolite and the modified zeolites with 10, 20, and $30 \mathrm{wt} . \%$ of $\mathrm{H}_{3} \mathrm{PO}_{4}$ displayed the desorption temperature ranges of $373-423 \mathrm{~K}, 423-523 \mathrm{~K}$, 523-673 K, and 673-823 K, which are assigned to extremely weak, weak, moderate, and strong acid sites, respectively [74]. The $\mathrm{NH}_{3}$-TPD profile of parent $\mathrm{Y}$ zeolite showed two peaks at $500 \mathrm{~K}$ and $686 \mathrm{~K}$, which correspond to weak and strong acid sites. Interestingly, the weak and strong acid sites of $Y$ zeolite were changed to be moderate acid sites after the phosphoric treatment. Moreover, the total amount of acid sites was reduced from $12.3 \mathrm{mmol} / \mathrm{g}$ of the parent $\mathrm{Y}$ sample to $3.4,4.7$, and $6.0 \mathrm{mmol} / \mathrm{g}$ of the 10,20 , and $30 \mathrm{wt} . \%$ of $\mathrm{H}_{3} \mathrm{PO}_{4}$ treated $\mathrm{Y}$ zeolite catalysts, respectively. This may indicate that acid modification with phosphoric acid may reduce the acid strength and the total acidity of $\mathrm{Y}$ zeolite. In addition, the effect of steam treatment on ZSM-5 zeolites on the acidic properties was also studied by the $\mathrm{NH}_{3}$-TPD technique [38]. It was found that the steam treated ZSM-5 samples display lower desorption temperature of the strong acid sites, indicating lower acid strength compared to the parent sample. Moreover, the strong acidity dramatically decreased after the steam treatment at higher than $450{ }^{\circ} \mathrm{C}$. The decrease of strong acid sites is caused by the dealumination process and the conversion of framework tetrahedral $\mathrm{Al}$ sites to aluminum hydroxide, resulting from the steam treatment procedure. Recently, the acidic properties of isolated ZSM-5 zeolite, hierarchical ZSM-5@Silicalite-1 nanosheet coreshell material, and conventional ZSM-5@Silicalite-1 composite samples were examined by the $\mathrm{NH}_{3}$-TPD technique, and the results are shown in Figure 6 [75]. The $\mathrm{NH}_{3}-\mathrm{TPD}$ profiles displayed two main desorption peaks at low and high desorption temperatures, which are attributed to the weak and strong acid sites, respectively. Remarkably, the strong acid density of hierarchical ZSM-5@Silicalite-1 nanosheet core-shell material was significantly lower than that of the isolated ZSM-5 core. This behavior may confirm that the Silicalite-1 nanosheet shell without acidity was successfully grown over the high acidity ZSM-5 core. 


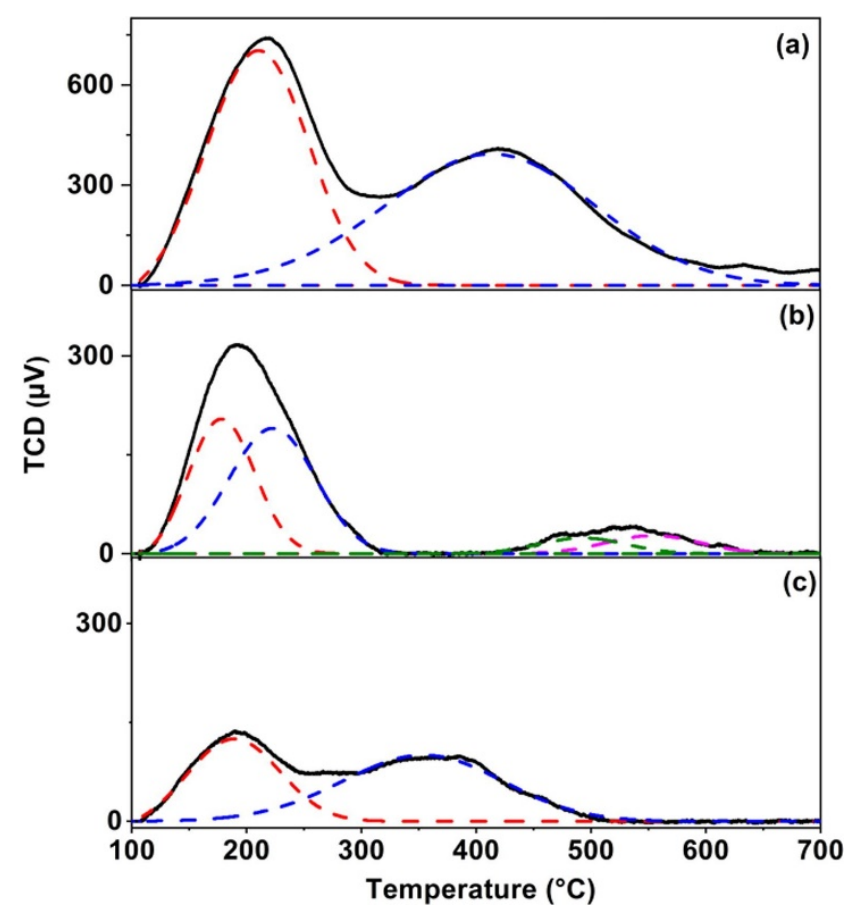

Figure 6. $\mathrm{NH}_{3}$-TPD profiles of (a) isolated ZSM-5 zeolite, (b) hierarchical ZSM-5@Silicalite-1 nanosheet composite, and (c) conventional ZSM-5@Silicalite-1 material. Reprinted with permission from [75]. Copyright 2020 Elsevier.

Fourier transform infrared spectroscopy (FTIR) of pyridine adsorption is a popular technique for the quantitative and qualitative analysis of Brønsted and Lewis acid sites in zeolite materials. The FTIR of pyridine adsorption was used to identify the Brønsted and Lewis acidity of $\mathrm{Li}, \mathrm{Zn}$, and Hf metals incorporated MFI zeolite catalysts [15]. From the pyridine-FTIR spectra, the bands at $1543 \mathrm{~cm}^{-1}, 1610$ and $1450 \mathrm{~cm}^{-1}$, and $1490 \mathrm{~cm}^{-1}$ were attributed to the pyridine interacted with Brønsted acid sites (BAS), Lewis acid sites (LAS), and both LAS and BAS, respectively [76,77]. The pyridine-FTIR spectra of ZnHfand LiZnHf-microporous MFI samples presented only the bands of LAS with low amounts of 18 and $14 \mu \mathrm{mol} / \mathrm{g}$, respectively. In contrast, the larger amount of LAS $(36 \mu \mathrm{mol} / \mathrm{g})$ and the small amount of BAS were observed in the ZnHf-MFI nanosheet catalyst. Interestingly, the disappearance of the BAS band and the similar amount of LAS $(32 \mu \mathrm{mol} / \mathrm{g})$ were found after Li introduction (LiZnHf-MFI nanosheet), indicating that the Li treatment process can eliminate the BAS but still preserve the LAS of the catalyst.

The FTIR of pivalonitrile (Pn) and 2,6-di-tert-butylpyridine (dTBPy) adsorption can be applied to investigate the accessibility of acid sites [78,79]. The size of dTBPy molecule is too big for the 10-membered ring micropores; therefore the dTBPy is suitable to use as a probe molecule to selectively examine the acid sites at the external or mesoporous surface of zeolite catalysts. In contrast, the Pn molecule is small and can enter the 10-membered ring channels so that it can detect the acid sites at the mesoporous surface and the micropore entrances [72]. The accessibility factors for dTBPy $\left(\mathrm{AF}_{\mathrm{dTBPy}}\right)$ and $\mathrm{Pn}\left(\mathrm{AF}_{\mathrm{Pn}}\right)$ molecules were calculated by the amount of acid sites measured by the adsorption of dTBPy and Pn molecules divided by the amount of acid sites determined by pyridine adsorption, respectively. The FTIR of these two molecules adsorption was applied with various types of ZSM-5 zeolites [25]. The $\mathrm{AF}_{\mathrm{dTBPy}}$ of microporous ZSM-5 was very low according to the non-mesoporous material. The desilicated ZSM-5 zeolites exhibited higher $\mathrm{AF}_{\mathrm{dTBPy}}$ corresponding to higher mesopore volume compared to the parent one. Moreover, the ultrathin and mesoporous ZSM-5 zeolites showed very high $\mathrm{AF}_{\mathrm{dTBPy}}$ relating to their high mesoporosity. For the $\mathrm{AF}_{\mathrm{Pn}}$, all samples displayed higher value than the $\mathrm{AF}_{\mathrm{dTBPy}}$ except the one of mesoporous samples. This sample showed the similar value between $\mathrm{AF}_{\mathrm{Pn}}$ and 
$\mathrm{AF}_{\mathrm{dTBPy}}$ because the mouths of micropores in this catalyst were obstructed by the Lewis acidic extra-framework sites.

Another probe molecule that can be used for the examination of acidic sites in zeolite catalysts is carbon monoxide (CO). The adsorption of $\mathrm{CO}$ on the zeolite catalyst surfaces can occur in the interactions between $\mathrm{CO}$ and various surface species, resulting in the different shifting of wavenumber referred to the $2138 \mathrm{~cm}^{-1}$ of physisorbed CO band [80,81]. This shifting can be assigned to each acidic species. Moreover, the $\mathrm{CO}$ molecules can also detect all acid sites of zeolite catalysts because of their small size. The FTIR of CO adsorption was employed to examine the acidities of parent BEA zeolites, dealuminated BEA samples, and $\mathrm{Zr}$ incorporated dealuminated BEA catalysts [63]. The $\mathrm{CO}$ adsorption experiment was performed at low temperature of a vacuum cell cooled by liquid nitrogen. The FTIR spectra were collected after the appearance of the physisorbed $\mathrm{CO}$ band or the saturation system, as can be seen in Figure 7. From the CO-FTIR spectra of the parent BEA zeolites, the bands at $2174 \mathrm{~cm}^{-1}, 2228$ and $2190 \mathrm{~cm}^{-1}$, and $2156 \mathrm{~cm}^{-1}$ were assigned to the adsorption of CO at $\mathrm{Al}$ Brønsted acidic sites, Lewis acidic sites, and surface silanol groups, respectively. The intensity of the BAS band was enhanced as a function of the decrease of $\mathrm{Si} / \mathrm{Al}$ ratio of the parent BEA zeolites, indicating that the amount of BAS increased with the Al content in the zeolite catalysts. Moreover, the LAS bands were not observed in the BEA zeolites with high $\mathrm{Si} / \mathrm{Al}$ ratios $(\mathrm{BEA}(38)$ and $\mathrm{BEA}(75))$, demonstrating the perfect zeolite framework without the Al extra-framework sites. For the dealuminated BEA samples, the amount of BAS dramatically decreased compared to the parent zeolites. In addition, there were not any LAS bands observed in the CO-FTIR spectra of dealuminated zeolites. This may indicate that the dealumination process removes the LAS and reduces the BAS of the BEA zeolites. After the $\mathrm{Zr}$ incorporation, the additional band at $2188 \mathrm{~cm}^{-1}$ was observed, and it corresponded to the Lewis acid sites of $\mathrm{Zr}$ atoms bonded to three oxygen framework atoms and one $\mathrm{OH}$ group [80]. It was found that the amount of this acidity relates to the $\mathrm{Zr}$ content on the BEA samples.
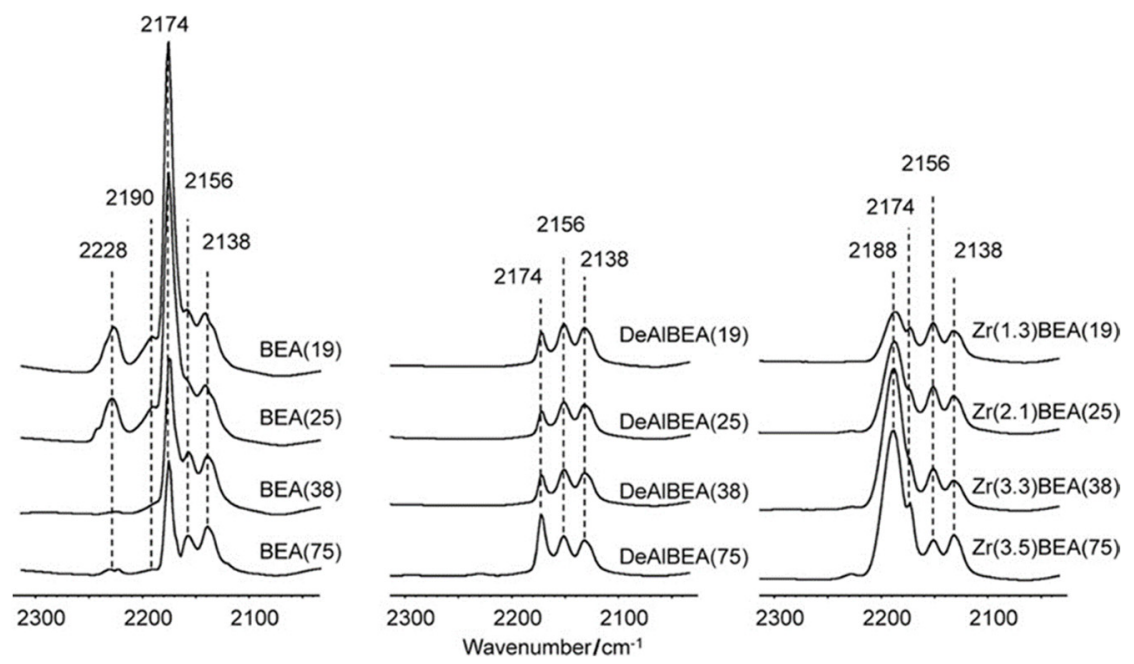

Figure 7. FTIR spectra of $\mathrm{CO}$ adsorption over the parent, dealuminated, and Zr incorporated dealuminated BEA zeolites. Reprinted with permission from [63]. Copyright 2016 WILEY-VCH Verlag GmbH \& Co. KGaA, Weinheim.

Apart from the characterization of acidic properties, the FTIR of pyrrole and $\mathrm{CDCl}_{3}$ adsorption can be used for the investigation of basic properties. These two techniques were applied with the Ta-BEA and MTa-BEA catalysts where $\mathrm{M}$ is $\mathrm{Ag}, \mathrm{Cu}$, or $\mathrm{Zn}$ and the FTIR results are shown in Figure 8 [65]. For the FTIR spectra of pyrrole adsorption, the shoulder band at $3390 \mathrm{~cm}^{-1}$ was found in all BEA catalysts, indicating the existence of weak basic sites [82]. In the case of $\mathrm{CDCl}_{3}$-FTIR spectra, the Ta-BEA sample showed the bands at 2258 and $2224 \mathrm{~cm}^{-1}$, which are attributed to weak and medium basic sites, respectively [83]. 
Interestingly, the FTIR spectra of MTa-BEA catalysts presented only the band of weak basic sites at $2256 \mathrm{~cm}^{-1}$, indicating that the introduction of $\mathrm{Ag}, \mathrm{Cu}$, or $\mathrm{Zn}$ into the Ta-BEA causes the removal of medium basic sites. Moreover, the MTa-BEA catalysts exhibited lower amounts of weak basic sites, especially the CuTa-BEA and ZnTa-BEA samples compared to the Ta-BEA zeolite. In addition, the metal species in the MTa-BEA catalysts were studied by X-ray photoelectron spectroscopy (XPS) [65]. From the XPS results, the range of Ta $4 f_{7 / 2}$ and $4 \mathrm{f}_{5 / 2}$ showed the bands at 24.8-25.2 and 29.1-29.2 eV, respectively, which are $\mathrm{Ta}(\mathrm{V})$ characteristics with good dispersion on the zeolite surfaces [84]. The Ag $3 d_{5 / 2}$ and $3 d_{3 / 2}$ characteristics were observed at the binding energy of 368.65 and $374.6 \mathrm{eV}$, demonstrating the clusters of oxidized $\mathrm{Ag}$ and $\mathrm{Ag}(\mathrm{I})$ species, respectively $[85,86]$. In the case of $\mathrm{Cu}$, the XPS spectrum displayed the bands at $953.3 \mathrm{eV}$ of $2 \mathrm{p}_{1 / 2}$ and $933.3 \mathrm{eV}$ of $2 \mathrm{p}_{3 / 2}$ indicating the $\mathrm{Cu}$ (II) species with good dispersion and strong interaction with the BEA zeolite [87]. For the ZnTa-BEA catalyst, the bands at 1022.5 and $1045.5 \mathrm{eV}$ were observed for $\mathrm{Zn} 2 \mathrm{p}_{3 / 2}$ and $2 \mathrm{p}_{1 / 2}$, respectively, which can be assigned to the $\mathrm{Zn}$ (II) species dispersed in the zeolite structure [88].
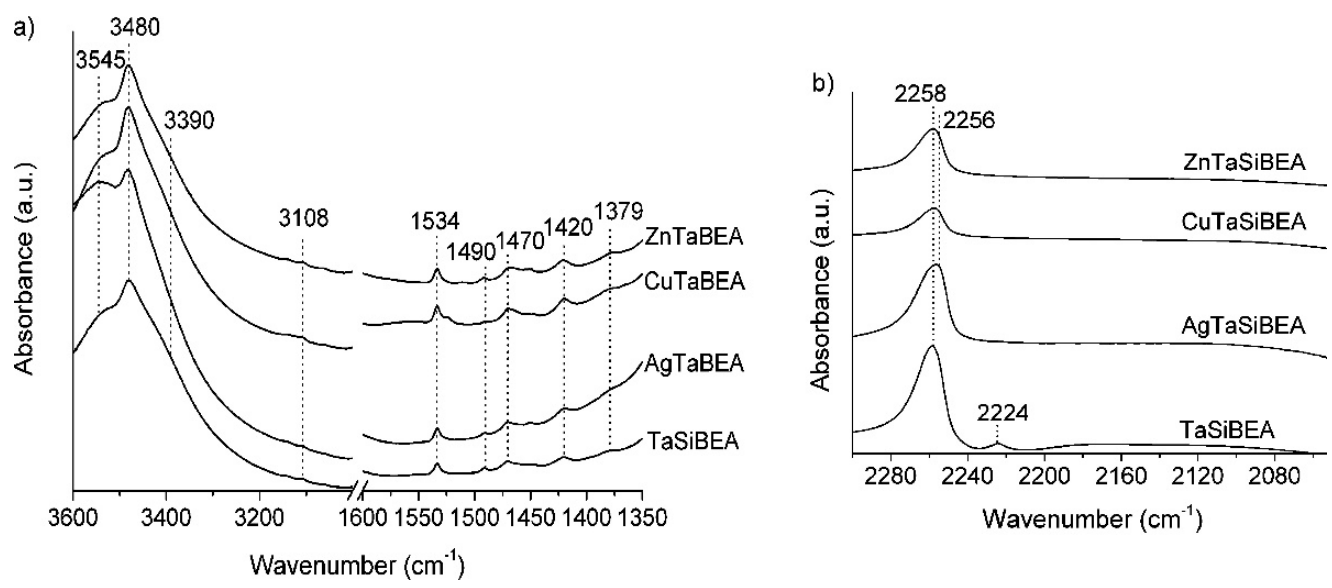

Figure 8. FTIR spectra of (a) pyrrole and (b) $\mathrm{CDCl}_{3}$ adsorption over the Ta-BEA and MTa-BEA catalysts where $\mathrm{M}$ is $\mathrm{Ag}, \mathrm{Cu}$, or $\mathrm{Zn}$. Reprinted with permission from [65]. Copyright 2017 American Chemical Society.

The characteristics of metal species in the zeolite catalysts can be also studied by the diffused reflectance UV-Vis and Raman spectroscopic techniques. The Zr supported on mesoporous $\mathrm{SiO}_{2}$, microporous MFI, and MFI nanosheet catalysts were characterized by both of the above-mentioned techniques [64]. The UV-vis diffuse reflectance spectrum of bulk $\mathrm{ZrO}_{2}$ showed the adsorption band at 230 to $240 \mathrm{~nm}$, which is attributed to the octahedral coordination structure [89]. For the $\mathrm{Zr}$ loaded on various supports, the blue shift to 205 to $215 \mathrm{~nm}$ was observed, indicating the ligand to metal charge transfer (LMCT) between $\mathrm{O}^{2-}$ and isolated $\mathrm{Zr}^{4+}$ in the tetrahedral structure [90]. Moreover, the UV-vis spectra of Zr supported on microporous MFI also display the shoulder band at $230 \mathrm{~nm}$ ascribed to the $\mathrm{Zr}-\mathrm{O}-\mathrm{Zr}$ linkages in nanoscopic regions. Remarkably, the Zr supported on the MFI nanosheet catalyst exhibited the highest absorbance edge energy of Zr, indicating the best dispersion of $\mathrm{Zr}$ oxide. For the Raman spectra of these three catalysts, the band at $637 \mathrm{~cm}^{-1}$ was attributed to the monoclinic $\mathrm{ZrO}_{2}$ and the bands at 550 and $476 \mathrm{~cm}^{-1}$ were attributed to the three-dimensional amorphous $\mathrm{ZrO}_{2}$ [91]. These bands showed very low intensity in the case of Zr supported on mesoporous silica and MFI nanosheet catalysts, demonstrating that the $\mathrm{ZrO}_{2}$ was highly dispersed without the formation of bulk $\mathrm{ZrO}_{2}$ species.

Furthermore, X-ray absorption is an efficient technique for the investigation of metal species in the zeolite catalysts. For example, the chemical states of Ce species in the Ce incorporated conventional and hierarchical ZSM- 5 zeolites were examined by X-ray absorption near the edge structure (XANES) [53]. It was found that the Ce oxidation state 
of the Ce loaded on hierarchical ZSM- 5 catalyst is mainly the $\mathrm{Ce}^{3+}$ species, whereas a high fraction of $\mathrm{Ce}^{4+}$ is observed in the case of a conventional ZSM-5 catalyst. This may indicate that the Ce species are well dispersed on the hierarchical ZSM- 5 surface because the $\mathrm{Ce}^{3+}$ species are generally found in the highly dispersed and very small Ce particles. In addition, the tungsten oxide $\left(\mathrm{WO}_{\mathrm{x}}\right)$ supported on MFI nanosheet catalysts with various $\mathrm{WO}_{\mathrm{x}}$ loading contents were characterized by extended X-ray absorption fine structure (EXAFS) and the XANES, and the results are shown in Figure 9 [54]. The XANES spectra of all catalysts presented an absorption band at $10,213 \mathrm{eV}$, which is assigned to the $\mathrm{W}^{6+}$ species in monoclinic $\mathrm{WO}_{3}$ [92]. From the fitting results of EXAFS, the $\mathrm{W}-\mathrm{O}$ bond distance of all catalysts was around $1.8 \AA$ corresponding to the bond distance between a tungsten atom and a nearest oxygen atom in the monoclinic $\mathrm{WO}_{3}$. Moreover, the coordination number $(\mathrm{CN})$ increased with an increase in tungsten oxide content confirming the larger particle size of tungsten oxide in the higher loading sample. In addition, the summary of the characterization perspectives of hierarchical zeolite catalysts is shown in Table S2.
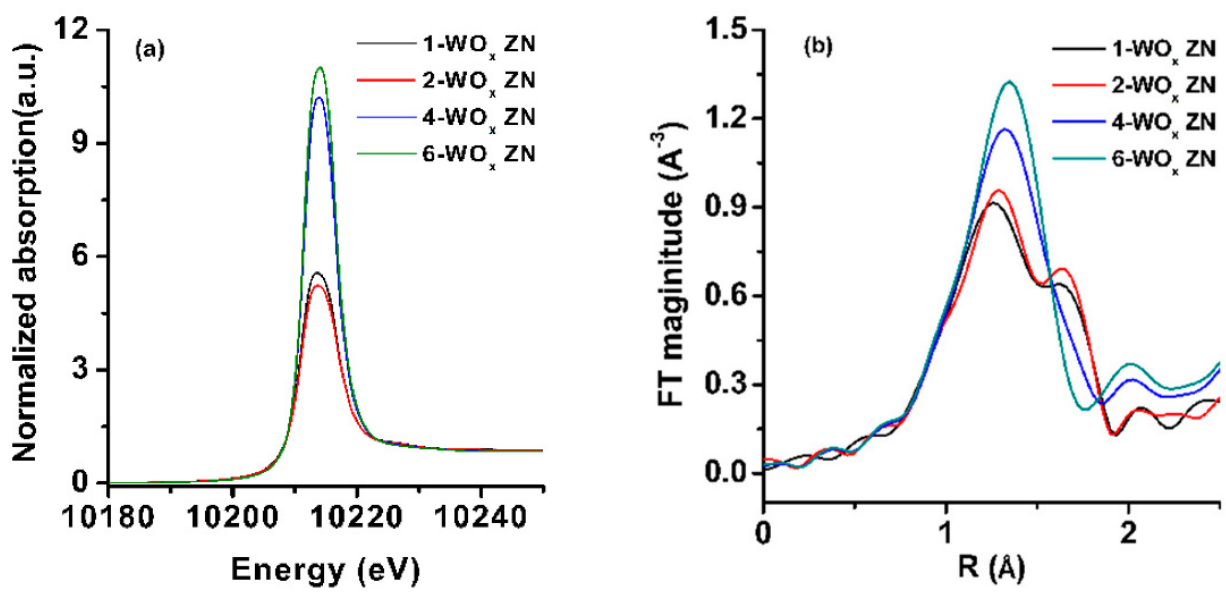

Figure 9. XANES (a) and EXAFS (b) spectra of the $\mathrm{WO}_{\mathrm{x}}$ supported on MFI nanosheet catalysts with various $\mathrm{WO}_{\mathrm{x}}$ loading contents. Reprinted with permission from [54].

\section{Catalytic Behaviors of Hierarchical Zeolites in Bioethanol Conversion to Monomers}

Hierarchical zeolites have been used as catalysts in various processes of bioethanol upgrading to monomers such as bioethanol dehdration, bioethanol to hydrocarbons, and bioethanol to butadiene. The catalytic activities and mechanistic studies of these catalytic circumstances over hierarchical zeolites have been reported as shown in the following sections.

\subsection{Catalytic Activities}

\subsubsection{Bioethanol Dehydration}

Bioethanol dehydration is one of the most popular catalytic applications in the production of monomers from bioethanol. To date, various hierarchical zeolite catalysts have been applied in this catalytic process. For example, the catalytic activity in ethanol dehydration to ethylene at the reaction temperature range from 100 to $300{ }^{\circ} \mathrm{C}$ was tested over the alkaline-acid treated zeolite L [37]. It was found that the treated zeolite L with high amounts of the acidic $\mathrm{Si}(\mathrm{OH}) \mathrm{Al}$ species exhibited the highest catalytic performance towards the ethylene production. However, the catalytic activity of zeolite $\mathrm{L}$ was reduced by an increased amount of the hydrogen bonded $\mathrm{Si}(\mathrm{OH}) \mathrm{Al} \cdots \mathrm{O}$ species. The highest ethanol conversion (99\%) and ethylene yield (96\%) were obtained at a $280{ }^{\circ} \mathrm{C}$ reaction temperature. Moreover, the modified zeolite L displayed high catalytic stability without the catalyst deactivation or the formation of higher hydrocarbons over the first $30 \mathrm{~h}$ of reaction time. In addition, the sequential alkaline and acid post-treated ZSM- 5 was also applied in this catalytic reaction [36]. Indeed, ethylene and diethyl ether were the competitive products in 
the catalytic ethanol dehydration at atmospheric pressure and $200{ }^{\circ} \mathrm{C}$. The ZSM- 5 zeolite after the sequential treatment exhibited the stable catalytic activity in ethanol dehydration to ethylene within $12 \mathrm{~h}$ of time-on-stream (TOS). Moreover, it was found that the weak acidity promoted the production of ethylene from this ethanol dehydration process. Subsequently, the dealuminated ZSM- 5 catalyst reached 98.5 and $100 \%$ of the ethylene yield and selectivity, respectively, from the ethanol dehydration at $220^{\circ} \mathrm{C}$ and $2.5 \mathrm{~h}^{-1}$ of weight hourly space velocity (WHSV) with $95 \%$ of the ethanol concentration [35]. Moreover, the phosphorous modified ZSM-5 exhibited 94.3 and $94.4 \%$ of the ethylene yield and selectivity, respectively when using $20 \%$ of the ethanol concentration at $1.5 \mathrm{~h}^{-1}$ of WHSV and $240{ }^{\circ} \mathrm{C}$ as the reaction temperature [35]. The zeolite $\mathrm{Y}$ was also modified with phosphoric acid and applied in the ethanol dehydration process [73]. The $\mathrm{H}_{3} \mathrm{PO}_{4}$ loading contents were varied from 10 to $30 \mathrm{wt} . \%$. It was found that the ethylene selectivity and ethanol conversion decreased with an increase of the $\mathrm{H}_{3} \mathrm{PO}_{4}$ content because of a decrease in pore volume and BET specific surface area because of the $\mathrm{H}_{3} \mathrm{PO}_{4}$ incorporation. However, the $10 \mathrm{wt} . \%$ of $\mathrm{H}_{3} \mathrm{PO}_{4}$ modified zeolite $\mathrm{Y}$ catalyst remarkably displayed high ethylene selectivity of $99 \%$ at $723 \mathrm{~K}$ reaction temperature and $16 \mathrm{kPa}$ of ethanol partial pressure. Recently, the pore-opened hierarchical MOR zeolite prepared by $\mathrm{NH}_{4} \mathrm{~F}$ etching was tested for catalytic ethanol/bioethanol dehydration activity, which was then compared to the parent MOR zeolite [49]. Remarkably, the pore-opened MOR zeolite exhibited higher catalytic performance than the parent one because of its higher mesoporosity. Furthermore, whereas the most area of treated MOR crystals can contribute to the dehydration reaction of ethanol because of its pore connectivity, the external surface of the parent MOR crystal mainly contributed to the reaction due to its small amount of closed mesopores. Another post-synthetic treatment with steaming of the ZSM-5 zeolite was performed to study the effect of the treatment process on the catalytic activity [38]. The catalytic results of the steam-treated and untreated ZSM-5 samples are presented in Figure 10. The steam treated ZSM-5 at $500{ }^{\circ} \mathrm{C}$ (HT500) clearly displayed higher catalytic stability according to its additional mesopores, lower acidity, and lower Brønsted/Lewis acid sites ratio after the steam treatment compared to the parent one (HZSM-5). Moreover, the steam treatment can also suppress the coke deposition in the porous structure of zeolite catalyst.

The catalytic performance in bioethanol dehydration to ethylene over nanoscale and microscale ZSM-5 catalysts was compared performing at $240^{\circ} \mathrm{C}$ in a fixed-bed reactor and at atmospheric pressure [93]. The nanosized ZSM-5 zeolite displayed stable bioethanol conversion and ethylene selectivity during $320 \mathrm{~h}$ of reaction time, whereas the catalytic activities of microscale ZSM- 5 catalyst decreased significantly from the initial state of the reaction when the $45 \%$ by volume bioethanol was used as the feedstock. In addition, the catalytic activities over various microporous and mesoporous ZSM- 5 zeolites were tested to study the influences of their acidic and textural properties on the catalytic behavior [25] The results revealed that the product selectivity depends on the accessibility and strength of the acid sites. Moreover, the higher catalytic activity and ethylene selectivity were observed when the intrinsic acidic properties and the micropore area were improved. Consequently, it may be concluded that the balance between microporosity and mesoporosity of the zeolite catalyst is the key factor to obtain the high catalytic performance because the responsibilities of micropores and mesopores are the catalyst reactivity and lifetime, respectively. Furthermore, the hierarchical SAPO-34@silicalite-1 and SAPO-34@ZSM-5 as core-shell materials were applied in the catalytic ethanol dehydration [94]. The results showed that the propylene and ethylene yields are improved over the SAPO-34@silicalite-1 and SAPO-34@ZSM-5 composite catalysts compared to the bare SAPO-34 zeolite. This catalytic enhancement related to the core-shell composite structure of the zeolite catalyst. It demonstrates that this study opens up the efficient utility of zeolite core-shell composite materials in the catalytic ethanol dehydration process. 

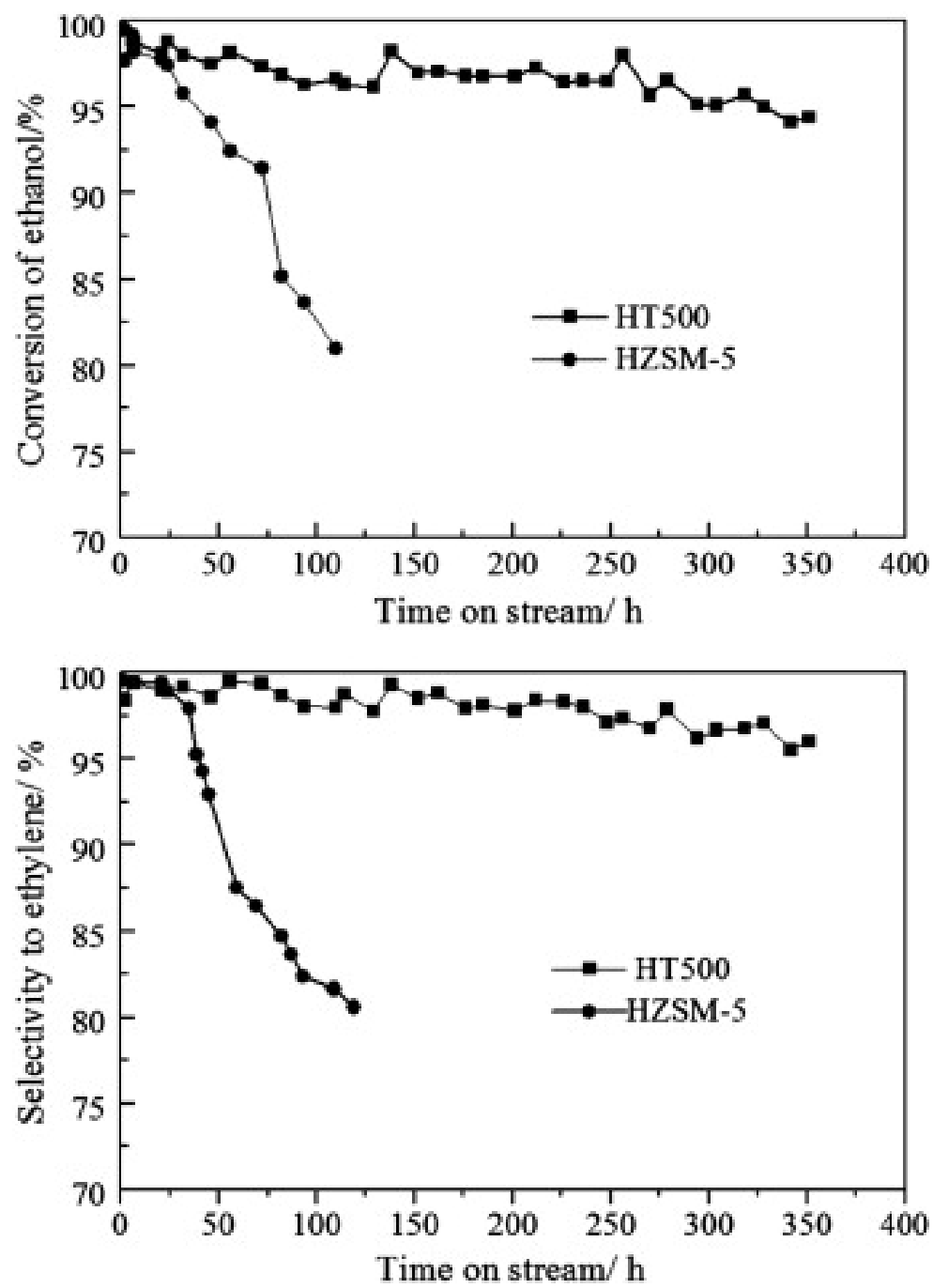

Figure 10. Ethanol dehydration catalytic activities of the steam treated (HT500) and parent (HZSM-5) ZSM-5 zeolites. Reprinted with permission from [38]. Copyright 2012 Elsevier B.V.

In the case of metal incorporated zeolite catalysts, there were various metal types reported and applied in the catalytic process of ethanol dehydration. For instance, the Ti loaded on dealuminated ZSM-5 catalyst was performed in the bioethanol dehydration using a flow micro-reactor at various conditions including 220,250 , and $280{ }^{\circ} \mathrm{C}$ reaction temperature and 7, 11, and $15 \mathrm{~h}^{-1}$ of WHSV [55]. Although the Ti-dealuminated ZSM5 catalyst exhibited low bioethanol conversion $(48 \%)$ at high WHSV $\left(15 \mathrm{~h}^{-1}\right)$ and low temperature $\left(220{ }^{\circ} \mathrm{C}\right)$, the reaction condition at $280{ }^{\circ} \mathrm{C}$ and $7 \mathrm{~h}^{-1}$ of WHSV provided high bioethanol conversion (96\%) and ethylene selectivity $(88 \%)$. In addition, the ceriaincorporated conventional and hierarchical ZSM-5 zeolites were compared in terms of the catalytic activity of ethanol dehydration [53]. The Ce supported on conventional ZSM-5 zeolite displayed very low ethylene selectivity and ethanol conversion due to the existence of bulk $\mathrm{CeO}_{2}$ structures. In contrast, the hierarchical ZSM-5 exhibited very high catalytic performance because of the high dispersion of Ce active species on zeolite surfaces. Furthermore, the $\mathrm{WO}_{\mathrm{x}}$ nanoparticles supported on MFI zeolite nanosheets with various $\mathrm{W}$ loadings (1-6 mol\%) were also studied in the catalytic dehydration of ethanol [54]. The ethanol conversion increased with the $\mathrm{W}$ loading content according to the higher amount of acidic sites. The catalyst with homogeneously distributed $\mathrm{WO}_{\mathrm{x}}$ nanoparticles exhibited slightly higher ethylene selectivity than the catalyst with nano-needle $\mathrm{WO}_{\mathrm{x}}$ structures at reaction temperatures above $390^{\circ} \mathrm{C}$. However, the needle-like $\mathrm{WO}_{\mathrm{x}}$ nanoparticles in the MFI nanosheet catalyst provided higher catalytic stability and were more suitable than 
the small-sized $\mathrm{WO}_{\mathrm{x}}$ nanoparticles in terms of ethylene yield for $8 \mathrm{~h}$ of reaction time. In 2020, the $\mathrm{Cu}$ containing zeolite catalyst synthesized via the one-pot method using the $\mathrm{Cu}$-tetraethylenepentamine (Cu-TEPA) as a copper precursor was reported to be a very active catalyst for the ethanol dehydration to ethylene [69]. The Cu-SSZ-13 zeolite catalyst exhibited higher than $99 \%$ of ethylene yield at low reaction temperature $\left(212^{\circ} \mathrm{C}\right)$ because of its medium and strong acid sites, which can be formed in the one-pot synthesis procedure. Moreover, the molybdenum and zinc bimetallic supported on aluminophosphate zeolite catalysts $\left(\mathrm{MoZn} / \mathrm{AlPO}_{4}-5\right)$ with various $\mathrm{Mo} / \mathrm{Zn}$ molar ratios $(2,4$, and 6$)$ were tested in ethanol dehydration [62]. It was found that the $\mathrm{MoZn} / \mathrm{AlPO}_{4}-5$ catalyst with the $\mathrm{Mo} / \mathrm{Zn}$ molar ratio of 4 is the most active catalyst for the ethylene production, whereas the pristine $\mathrm{AlPO}_{4}-5$ zeolite displays high product selectivity of diethyl ether. The formation of $\mathrm{ZnMoO}_{4}$ during the interactions of Mo and $\mathrm{Zn}$ oxides was considered to be a key process to improve the acidity, eventually promoting the ethylene formation in ethanol dehydration process.

\subsubsection{Bioethanol to Hydrocarbons}

Bioethanol conversion to hydrocarbons is one of the most promising processes for the production of various monomer types from the bio-based resources. The effects of reaction conditions and $\mathrm{Si} / \mathrm{Al}$ ratios of the $\mathrm{HZSM}-5$ catalyst on the product distributions in the ethanol to hydrocarbons were studied by Karthikeyan K. Ramasamy and Yong Wang [95]. The results displayed that the HZSM-5 zeolite with higher Si/Al ratios or lower acidity displays the faster catalyst deactivation and the higher amount of produced unsaturated compounds at the similar TOS. For the effect of reaction temperature, the faster catalyst deactivation regarding the formation of liquid hydrocarbons was observed at $300{ }^{\circ} \mathrm{C}$, while the higher temperature $\left(400{ }^{\circ} \mathrm{C}\right)$ produced more gaseous fractions and lower liquid range hydrocarbons. Moreover, the higher weight hourly space velocity (WHSV) affected the higher ethylene production. Subsequently, the catalytic activities of alkali-treated HZSM-5 zeolites with various $\mathrm{Si} / \mathrm{Al}$ ratios of 11.5, 19, and 26.5 were evaluated by the catalytic reaction of ethanol transformation into hydrocarbons (aromatics and light olefins) [34]. Under similar experimental conditions, the alkali-treated HZSM-5 catalysts exhibited higher ethanol conversion and high selectivity of $\mathrm{C}_{4}$ to $\mathrm{C}_{9}$ hydrocarbons compared to the parent catalysts. These behaviors correspond to the significant higher mesopore volume and external surface area without the significant loss of crystallinity after the alkaline treatment of the HZSM- 5 zeolites. In addition, it was found that the parent HZSM-5 zeolite with a $26.5 \mathrm{Si} / \mathrm{Al}$ ratio produces the maximum yield of aromatic compounds (benzene, toluene, xylenes, and ethylbenzene) and the minimum amount of ethylene at $450{ }^{\circ} \mathrm{C}, 20 \mathrm{bar}$, and $5 \mathrm{~h}^{-1}$ of reaction temperature, pressure, and WHSV, respectively. The another post-treated $\mathrm{ZSM}-5$ zeolite with $\mathrm{NH}_{4} \mathrm{~F}$ solutions was applied in the catalytic selective conversion of bioethanol to propene at $500^{\circ} \mathrm{C}$, atmospheric pressure, and $10 \mathrm{~h}^{-1}$ of WHSV [43]. The additional mesopores formed by the $\mathrm{NH}_{4} \mathrm{~F}$ treatment can facilitate the mass transfer and reduce the acid strength, resulting in coke formation suspension. Furthermore, the enhancement of propene selectivity and catalytic stability were found in the case of fluorine modified ZSM- 5 catalyst with the optimal content (20 wt.\%). Apart from the coke formation, the removal of $\mathrm{Al}$ in the zeolite structure was also an important factor affecting the deactivation of the fluorinated ZSM- 5 catalyst.

The catalytic activity of hierarchical nano-sized ZSM- 5 zeolite was compared to that of conventional ZSM- 5 zeolite in the ethanol conversion into hydrocarbons performing on a fixed-bed reactor at $360^{\circ} \mathrm{C}$ temperature, 300 psig of pressure, and $7.9 \mathrm{~h}^{-1}$ of WHSV [26]. The results illustrated that the lifetime of nano-sized ZSM- 5 catalyst is approximately two times higher than that of the conventional one, although the quantity of coke deposited on the hierarchical ZSM- 5 is approximately 1.6 times higher with respect to the conventional zeolite with the low $\mathrm{Si} / \mathrm{Al}$ ratio samples $(\sim 40)$. For the high $\mathrm{Si} / \mathrm{Al}$ ratio zeolites $(\sim 140)$, the deposited coke amount and catalytic lifetime of hierarchical nanocrystalline ZSM-5 zeolite were higher than those of the conventional catalyst by about 2.1 and 5 times, respectively. These results were because of the higher mesoporosity of hierarchical nano-sized ZSM-5 
catalyst, resulting in a lower diffusion path length; therefore molecular transport inside the zeolite framework was improved with respect to the conventional ZSM-5 catalyst. The catalytic activity of another nanosized zeolite with CHA framework was also studied and compared to the conventional CHA zeolite [32]. The product distribution of both CHA zeolite catalysts was significantly different even though the ethanol conversion was the same $(100 \%)$. The nanosized CHA zeolite displayed $61.9 \%$ and $19.6 \% \mathrm{C}_{2} \mathrm{H}_{4}$ and $\mathrm{C}_{3} \mathrm{H}_{6}$ yields, respectively, while the conventional catalyst exhibited $85.7 \%$ yield of $\mathrm{C}_{2} \mathrm{H}_{4}$ and $10.4 \%$ yield of $\mathrm{C}_{3} \mathrm{H}_{6}$. The lower propylene yield and higher ethylene yield over the micron-sized CHA catalyst indicate the fast catalyst deactivation due to the coke formation on catalyst surfaces. Moreover, it was found that different catalytic stability depended on different external surface areas, resulting in different amounts of carbonaceous deposition and catalytic deactivation. In 2016, the hierarchical mesoporous ZSM-5 synthesized using the HZSM-5 zeolite as a seed was applied in the catalytic conversion of bioethanol [13]. The reaction was performed in a U-tube fixed-bed reactor at $450{ }^{\circ} \mathrm{C}$ for 4 days. The main fraction of gas products obtained from the mesoporous ZSM- 5 catalyst was ethylene, whereas the HZSM-5 catalyst provided an increase in mixed $\mathrm{C}_{4}$ gas product, propylene, and ethylene selectivity and a decrease in propane selectivity. Moreover, the HZSM-5 zeolite also produced the bulky hydrocarbons such as $C_{9}$ and $C_{10+}$ aromatics after $96 \mathrm{~h}$ of TOS. In contrast to the hierarchical mesoporous ZSM-5 catalyst, a decrease in $\mathrm{C}_{10+}$ aromatic selectivity was observed with an increase of TOS. However, the mesoporous zeolite exhibited much higher production amount of bulky hydrocarbons including kerosene and gas oil.

The effect of textural properties of the ZSM-5 zeolite catalysts on the catalytic conversion of ethanol to hydrocarbons was studied at $623 \mathrm{~K}$ and 3.0 MPa of pressure [42]. It was reported that the catalyst lifetime was not related to the rate of coke formation but corresponded to the amount of pore mouths of the zeolite catalysts. The additional macropores or mesopores obtained by the fluoride or alkaline leaching of microporous zeolites can increase the amount of pore mouths and decrease the diffusion path length of molecules in the zeolite micropores. Nevertheless, the hierarchical nanometer-sized zeolite was the most efficient catalyst, which can prolong the catalyst lifetime above $100 \mathrm{~h}$ even though most of the acid sites were destroyed. In addition, the influences of textural properties and crystal size of various BEA-type zeolites including micron-sized, nanometer-sized, and nano-sponge crystals on the catalytic ethanol transformation into hydrocarbons were also investigated at $350{ }^{\circ} \mathrm{C}$ and $3.0 \mathrm{MPa}$ of pressure [28]. The nanosized and micron-sized BEA zeolites displayed the complete ethanol conversion while the nano-sponge BEA catalyst exhibited slightly lower ethanol conversion at the initial state of the reaction because of fewer Brønsted acid sites (BAS). However, the rate of catalyst deactivation was on the order of micron-sized $>>>$ nanometer-sized $>$ nano-sponge corresponding to the higher mesoporosity of hierarchical zeolites. For the comparison between nanosized and nanosponge zeolite crystals, the nano-sponge BEA catalyst showed higher catalytic stability due to its higher ordered mesoporous network. Interestingly, the hierarchical ZSM-5 zeolites prepared by various methods including the unbiased $\mathrm{NH}_{4} \mathrm{~F}$ etching $\left(\mathrm{Z}_{\mathrm{F}}\right)$, Si-biased caustic leaching $\left(Z_{B}\right)$, and nanosheet templating $\left(Z_{N S}\right)$ were examined in the catalytic behavior of ethanol conversion to hydrocarbons [45]. The catalytic results are shown in Figure 11, where $Z_{p}$ is the parent $Z S M-5$ zeolite. The $Z_{p}$ sample displayed very low catalytic activity with only $35 \%$ of the initial $C_{3+}$ yield and rapid catalyst deactivation. For the $Z_{\mathrm{B}}$ catalyst, almost $100 \%$ of $C_{3+}$ yield was observed at the initial stage, but it dramatically dropped as a function of TOS, indicating the fast catalyst deactivation. Although the $Z_{N S}$ sample illustrated lower initial $C_{3+}$ yield due to its much lower number of BAS compared to the $Z_{B}$ catalyst, the deactivation rate of $Z_{N S}$ was lower than that of the $Z_{B}$. Remarkably, the $Z_{\mathrm{F}}$ catalyst exhibited the highest catalytic stability and could still produce $60 \mathrm{~mol} \%$ of $C_{3+}$ yield after $90 \mathrm{~h}$ of TOS according to the mesopore connectivity of house-of-cards-like pore structure obtained by the unbiased $\mathrm{NH}_{4} \mathrm{~F}$ etching of ZSM- 5 zeolite. 


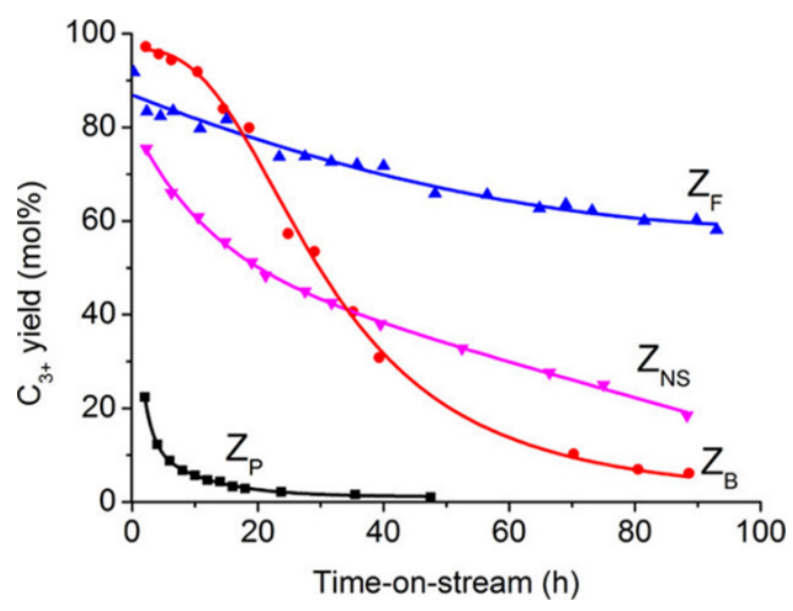

Figure 11. Catalytic activity of ethanol conversion over the parent $Z S M-5$ zeolite $\left(Z_{\mathrm{p}}\right), \mathrm{NH}_{4} \mathrm{~F}$ etched ZSM-5 zeolite $\left(Z_{F}\right)$, desilicated ZSM-5 zeolite $\left(Z_{B}\right)$, and ZSM-5 nanosheet $\left(Z_{N S}\right)$. Reprinted with permission from [45]. Copyright 2019 American Chemical Society.

The metal incorporated zeolite catalysts were also applied in the ethanol conversion to hydrocarbons. For example, the catalytic activity of Ni/HZSM-5 zeolite was investigated using the conversion of ethanol/bioethanol to high value hydrocarbons [57]. The results showed that the Ni/HZSM-5 catalyst illustrated the high capability of aromatics and gaseous hydrocarbons production at lower WHSV. For comparison between bare HZSM-5 and Ni/HZSM-5 zeolites, both of the catalysts displayed the similar product distribution at various concentrations of ethanol feed. Moreover, they also exhibited stable conversions at $87 \%$ and $90 \%$ during $168 \mathrm{~h}$ of reaction time for the bare HZSM- 5 and Ni/HZSM- 5 catalysts, respectively. The bimetallic InV-ZSM-5 zeolite was also applied in this catalytic reaction and compared with the monometallic In- and V-ZSM-5 catalysts [61]. The InV-ZSM-5 zeolite displayed much lower ethylene production with respect to the V-ZSM-5 at 250 to $350{ }^{\circ} \mathrm{C}$ reaction temperature, but the different ethylene selectivity was not observed in the temperature range from 350 to $450{ }^{\circ} \mathrm{C}$. Moreover, the bimetallic InV-ZSM-5 catalyst illustrated higher yield of valuable $\mathrm{C}_{3+}$ products compared to the In- and V-ZSM- 5 catalysts at 250 to $450{ }^{\circ} \mathrm{C}$ and 250 to $350{ }^{\circ} \mathrm{C}$, respectively. Interestingly, the product distribution of InV-ZSM- 5 catalyst was $19 \%$ of $C_{3}$ to $C_{4}$ olefins, $35 \%$ of $C_{3}-C_{4}$ paraffins, and $33 \%$ of $C_{5+}$ liquid fractions. From the product analysis, the $\mathrm{C}_{5+}$ liquid fractions contained more than 350 compounds including $6.5 \%$ of olefins, $24.0 \%$ of iso-paraffins, $3.8 \%$ of paraffins, $4.2 \%$ of unidentified products, $60.2 \%$ of aromatics, and $5.4 \%$ of naphthenes.

\subsubsection{Bioethanol to Butadiene}

Bioethanol conversion to butadiene consists of five main reaction steps including: (i) dehydrogenation of bioethanol to acetaldehyde; (ii) aldol condensation of acetaldehyde to acetaldol; (iii) dehydration of acetaldol to crotonaldehyde; (iv) reduction of crotonaldehyde to crotyl alcohol; and (v) dehydration of crotyl alcohol to butadiene [96]. This catalytic process requires the active metal species, which can act as the efficient Lewis acidic sites. The catalytic activities over $\mathrm{MgO}$ impregnated on microporous and mesoporous LTA zeolites were investigated in the transformation of acetaldehyde and ethanol mixture into butadiene [40]. Interestingly, the catalytic activity significantly increased with an increase of the pore width of zeolite catalysts. While the microporous MgO/LTA catalyst displayed $23 \%$ of ethanol conversion, the mesoporous $\mathrm{MgO} / \mathrm{LTA}$ zeolite reached $45 \%$ of ethanol conversion. Moreover, the high amount of croton aldehyde and high polar $\mathrm{C}_{4}$ compound, which are the intermediates in the ethanol to butadiene process, were produced in the case of the mesoporous catalyst. This catalytic behavior may confirm the potential of the mesoporous $\mathrm{MgO} / \mathrm{LTA}$ zeolite for the application in this catalytic process. Subsequently, the $\mathrm{Zr}$ incorporated microporous and mesoporous BEA zeolites were tested in the catalytic 
conversion of acetaldehyde and ethanol to butadiene to study the effect of intracrystalline mesopores on the catalytic activity [41]. For the ethanol-acetaldehyde conversion, although the initial conversion over microporous and mesoporous Zr-BEA catalysts showed similar values between $55 \%$ and $58 \%$, it dramatically dropped to $35 \%$ after $6 \mathrm{~h}$ of TOS when using the microporous sample, whereas the conversion of mesoporous Zr-BEA catalyst slowly dropped from $58 \%$ to $44 \%$. Moreover, the butadiene selectivity also presented the similar trend with the conversion of acetaldehyde and ethanol mixture. While the butadiene selectivity over the microporous catalyst decreased sharply from $75 \%$ to $59 \%$ after 6 h of TOS, the mesoporous catalyst still maintained more than $60 \%$ of butadiene selectivity at $6 \mathrm{~h}$ of TOS. These catalytic behaviors indicate the benefit of intracrystalline mesopores for the improvement of catalytic activity over zeolite catalysts.

The catalytic activity of bimetallic $\mathrm{Mg}-\mathrm{ZrO} \mathrm{x}_{\mathrm{x}} / \mathrm{MFI}$ nanosheet catalysts was investigated and compared with the monometallic $\mathrm{Zr}$ loaded on various supports including commercial $\mathrm{SiO}_{2}$, microporous MFI, and hierarchical MFI nanosheets using the two-step method in a dual fixed-bed reactor system [64]. The feedstock stream of acetaldehyde-ethanol mixture was in-situ generated in the first fixed-bed reactor using $1 \mathrm{~g}$ of $20 \% \mathrm{Cu} / \mathrm{SiO}_{2}$ as a catalyst and ethanol as a reactant. The catalytic transformation of the acetaldehyde-ethanol mixture into butadiene was then performed in the second fixed-bed reactor. The $16 \% \mathrm{Zr} / \mathrm{MFI}$ nanosheet catalyst provided higher catalytic performance with $42.3 \%$ of butadiene selectivity and $60.5 \%$ of conversion compared to the $\mathrm{Zr}$ loaded on commercial $\mathrm{SiO}_{2}$ and microporous MFI catalysts corresponding to the highest dispersion of $\mathrm{Zr}$ species over the MFI nanosheet support. The butadiene selectivity was improved to $54.7 \%$ after the incorporation of $1.2 \mathrm{wt} . \% \mathrm{Mg}$ into the $16 \% \mathrm{Zr} / \mathrm{MFI}$ nanosheet. For the effect of reaction conditions, it was found that the butadiene selectivity was enhanced to $74.6 \%$ when the reaction was performed at 1:2 of acetaldehyde to ethanol ratio, $1.44 \mathrm{~h}^{-1}$ of WHSV, and $350{ }^{\circ} \mathrm{C}$ reaction temperature. Remarkably, the $1.2 \% \mathrm{Mg}-16 \% \mathrm{Zr} / \mathrm{MFI}$ nanosheet catalyst exhibited high catalytic stability without the catalyst deactivation for 7 days or $168 \mathrm{~h}$ of reaction time. Furthermore, it was reported that the hierarchical nanosheet structure, fewer Brønsted acidic sites, and substantially weak Lewis acidic sites can promote the catalytic conversion of ethanol to butadiene with high stability, selectivity, and activity in the two-step reaction system.

Vitaly L. Sushkevich and Irina I. Ivanova reported the conversion of ethanol to butadiene using the Ag-promoted $\mathrm{Zr} / \mathrm{BEA}$ zeolite as a catalyst [63]. The catalytic activity over Ag-3.5\%Zr/BEA zeolite (Ag/Zr(3.5)BEA(75)) was compared to that of the parent BEA zeolite (BEA(75)), dealuminated BEA zeolite (DeAlBEA(75)), and Ag doped dealuminated BEA zeolite (Ag/DeAlBEA(75)) as shown in Figure 12. The BEA(75) and the DeAlBEA(75) produced only diethyl ether and ethylene, which are ethanol dehydration products. After the introduction of Ag into the dealuminated BEA (Ag/DeAlBEA(75)), a high amount of ethanol dehydrogenation product (acetaldehyde) and low amount of butadiene were observed, indicating the change of reaction pathway towards butadiene production. Interestingly, the $\mathrm{Ag} / \mathrm{Zr}(3.5) \mathrm{BEA}(75)$ catalyst exhibited the highest initial formation rate of butadiene due to the existence of active $\mathrm{Zr}$ Lewis acidic sites, which can promote the conversion of ethanol to butadiene.

The bimetallic ZnTa/BEA, CuTa/BEA, and AgTa/BEA zeolite catalysts were tested in ethanol conversion to butadiene in order to investigate the effect of metal doping into the monometallic Ta/BEA catalyst on their catalytic performances [65]. The results showed that the doping with $\mathrm{Zn}, \mathrm{Cu}$, and $\mathrm{Ag}$ can change the catalytic properties of the Ta/BEA catalyst because of the creation of additional dehydrogenation active sites and the modification of acid-base properties. These modifications accelerated the ethanol dehydrogenation to acetaldehyde and further conversion into butadiene. Remarkably, the CuTa/BEA catalyst illustrated the highest catalytic performance, with $88 \%$ of ethanol conversion and $73 \%$ of butadiene selectivity at $598 \mathrm{~K}$ reaction temperature and $0.5 \mathrm{~h}^{-1}$ of WHSV. In 2019, the catalytic activity of LiZnHf-MFI nanosheet catalyst was investigated and compared to that of the LiZnHf-MFI microporous zeolite [15]. The LiZnHf-MFI nanosheet catalyst 
exhibited $64.6 \%$ of ethanol conversion and $73.0 \%$ of butadiene selectivity while only $21.3 \%$ and $36.4 \%$ of ethanol conversion and butadiene selectivity, respectively, were observed in the case of LiZnHf-MFI microporous catalyst. The higher catalytic performance of LiZnHf-MFI nanosheet sample resulted from the synergistic effect between hierarchical nanosheet structure and appropriate acidity.

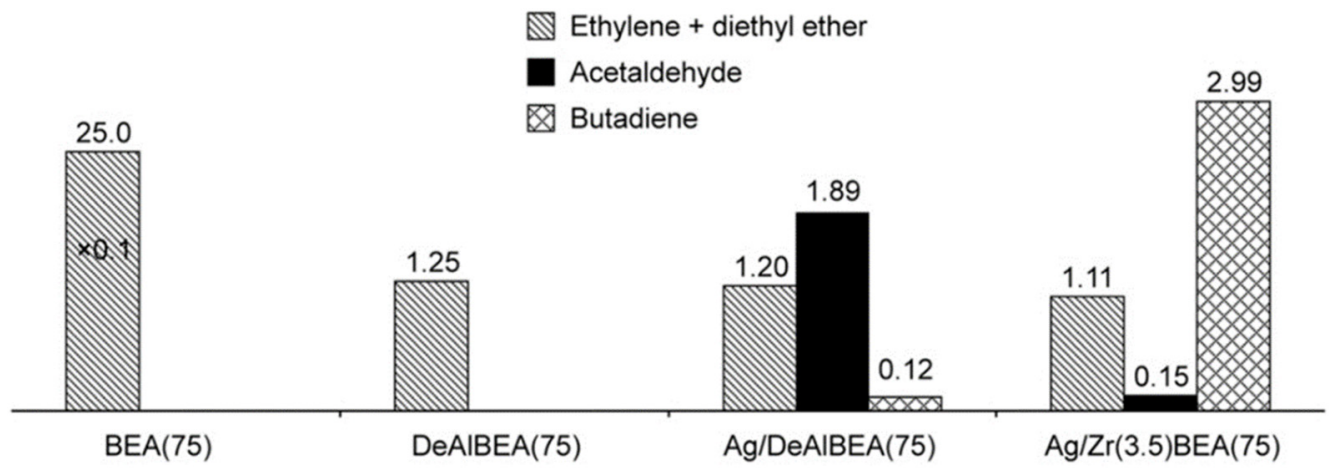

Figure 12. Initial formation rates of various products from the catalytic ethanol conversion over the BEA(75), DeAlBEA(75), Ag/DeAlBEA(75), and Ag/Zr(3.5)BEA(75) catalysts. Reprinted with permission from [63]. Copyright 2016 WILEY-VCH Verlag GmbH \& Co. KGaA, Weinheim.

\subsection{Mechanistic Studies}

Mechanistic studies in the ethanol conversion to monomers over zeolite catalysts have been examined by operando characterization techniques and theoretical calculations. For example, the MFI zeolite was performed by the IR operando study in ethanol dehydration at different reaction conditions [97]. The two main IR bands at 3320 and $3610 \mathrm{~cm}^{-1}$ were attributed to the ethanol dimer surface species and the Brønsted acid sites interacting with ethanol or the total coverage of dimer and monomer species, respectively. The mechanistic scheme of ethanol dehydration over MFI zeolite is composed of four pathways [97] and is illustrated in Figure 13. The first pathway (Mechanism 1) is the synthesis of diethyl ether (DEE) via an ethanol dimer intermediate. The second mechanism is the production of ethylene via an ethoxy intermediate. The third pathway is the decomposition of ethanol dimer intermediate to ethylene and ethanol molecules. For the last pathway (Mechanism $4)$, the ethoxy intermediate can react with another ethanol molecule to produce the DEE. From the IR operando results, it was found that the dimer-assisted etherification is the main pathway in the catalytic ethanol conversion at high ethanol pressures. An increase in the reaction temperature promoted the ethoxide-mediated route. Moreover, the ethylene was produced via the diethyl ether decomposition route and the ethoxide-mediated pathway at high ethanol conversion. Subsequently, the impact of different MFI zeolite morphology between 2D-nanosheet and 3D-conventional structures was examined by the operando FTIR spectroscopy combined with the determination of Brønsted acidic sites coverage and turnover rates at various reaction conditions to calculate the activation energies in the ethanol dehydration pathways [98]. The results showed that the first-order activation energy of 2D-MFI-nanosheet is $16 \pm 4 \mathrm{~kJ} / \mathrm{mol}$, which is lower than that of 3D-MFI-conventional ( $41 \pm 1 \mathrm{~kJ} / \mathrm{mol})$. From the analysis of thermodynamic and kinetic parameters, it was found that the reason for different intrinsic activity between MFI nanosheet and conventional zeolites is the different stabilization effect of adsorbed ethanol dimer and monomer surface species.

In 2019, in-situ and ex-situ solid-state NMR spectroscopy techniques were used to investigate the intermediate species in the dehydration of ethanol into ethylene over the H-ZSM-5 zeolite catalyst [99]. The triethyloxonium ion (TEO) was observed as an important intermediate species. Although the TEO was a stable species on the H-ZSM-5 surfaces but it showed high activity for the reaction. The zeolite was ethylated by the TEO species at lower temperatures to form the surface ethoxy species and further convert 
to ethylene. Furthermore, the theoretical calculations revealed that the TEO-ethoxidemediated pathway is preferable in the initial stage of the catalytic dehydration of ethanol into ethylene over the zeolite catalyst.

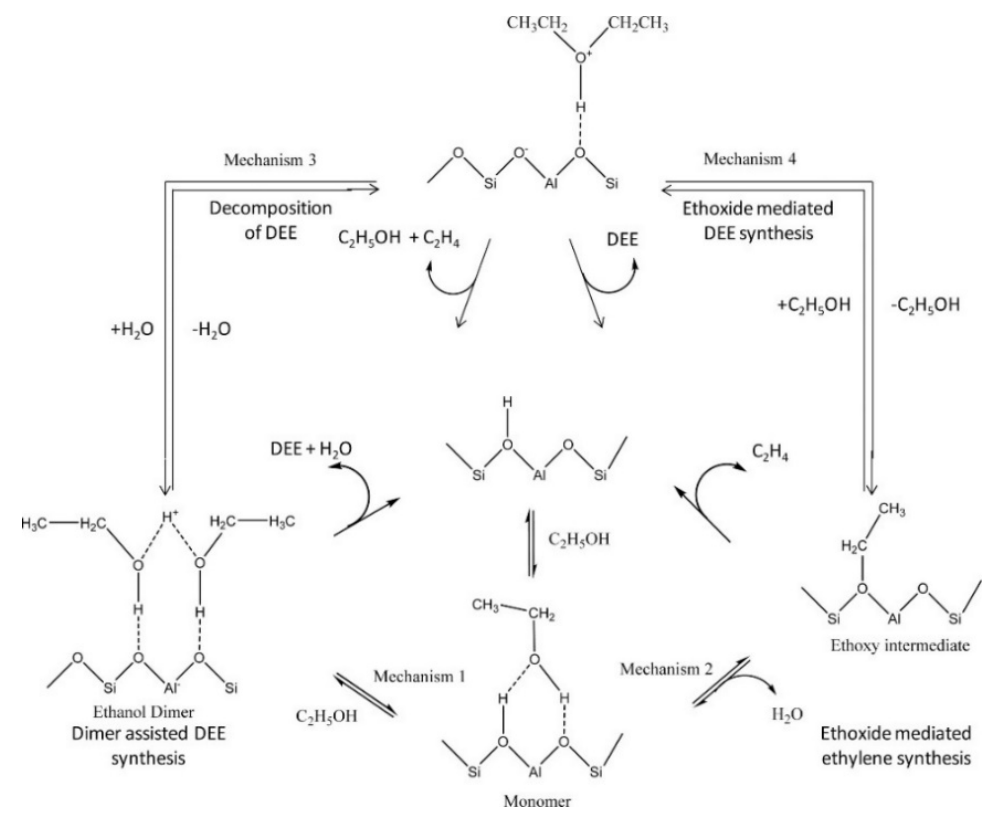

Figure 13. Mechanistic scheme of ethanol dehydration over MFI zeolite. Reprinted with permission from [97]. Copyright 2017 Elsevier B.V.

Generally, the mechanism of ethanol conversion to hydrocarbons consists of two main steps, including ethanol dehydration to ethylene and hydrocarbon production via the hydrocarbon pool mechanism, as shown in Figure 14 [100]. After the ethanol dehydration step, the produced ethylene molecules can undergo oligomerization and cracking reactions to form the higher alkenes and they can be further converted to aromatics and paraffins through the hydride transfer, cyclization, and aromatization reactions. In addition, the mechanistic studies in ethanol conversion into hydrocarbons over the bimetallic InV-ZSM5 zeolite catalyst were performed by the experiments with $\mathrm{C}_{2} \mathrm{H}_{5} \mathrm{OD}$ and in-situ diffuse reflectance fourier transform infrared spectroscopy (DRIFTS) analysis [61]. The results illustrated that the hydrocarbon pool mechanism is the main pathway for the production of hydrocarbons from ethanol over the InV-ZSM- 5 catalyst, whereas the dehydration step is less pronounced.

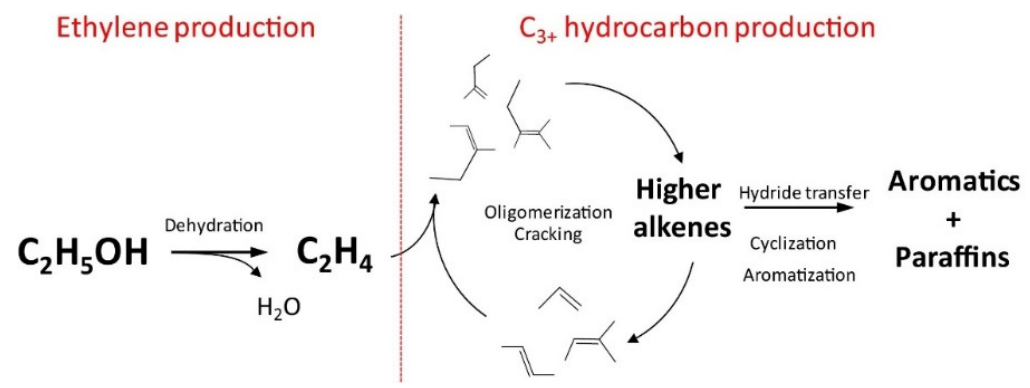

Figure 14. Mechanistic scheme of ethanol conversion to hydrocarbons over zeolite catalysts. Reprinted with permission from [100]. Copyright 2014 Elsevier B.V.

In 2018, the mechanistic study in catalytic transformation of ethanol into butadiene over bifunctional Zn-Y/BEA zeolite catalyst was performed by several techniques such as temperature-programmed surface reaction (TPSR), ethanol temperature-programmed 
desorption (TPD), and in-situ diffuse reflectance infrared Fourier transform spectroscopy (DRIFTS) to investigate the roles of $\mathrm{Zn}$ and $\mathrm{Y}$ active sites [101]. From these observations, the mechanism was proposed as shown in Figure 15. Interestingly, both of $\mathrm{Zn}$ and $\mathrm{Y}$ species in bifunctional $\mathrm{Zn}-\mathrm{Y} / \mathrm{BEA}$ zeolite were active for various reaction steps including ethanol dehydrogenation to acetaldehyde, aldol condensation of acetaldehyde to acetaldol, and Meerwein-Ponndorf-Verley (MPV) reduction of crotonaldehyde to crotyl alcohol. Moreover, it was found that the $\mathrm{Y}$ active sites present the higher coupling activity and lower dehydrogenation activity when compared to the $\mathrm{Zn}$ active sites.

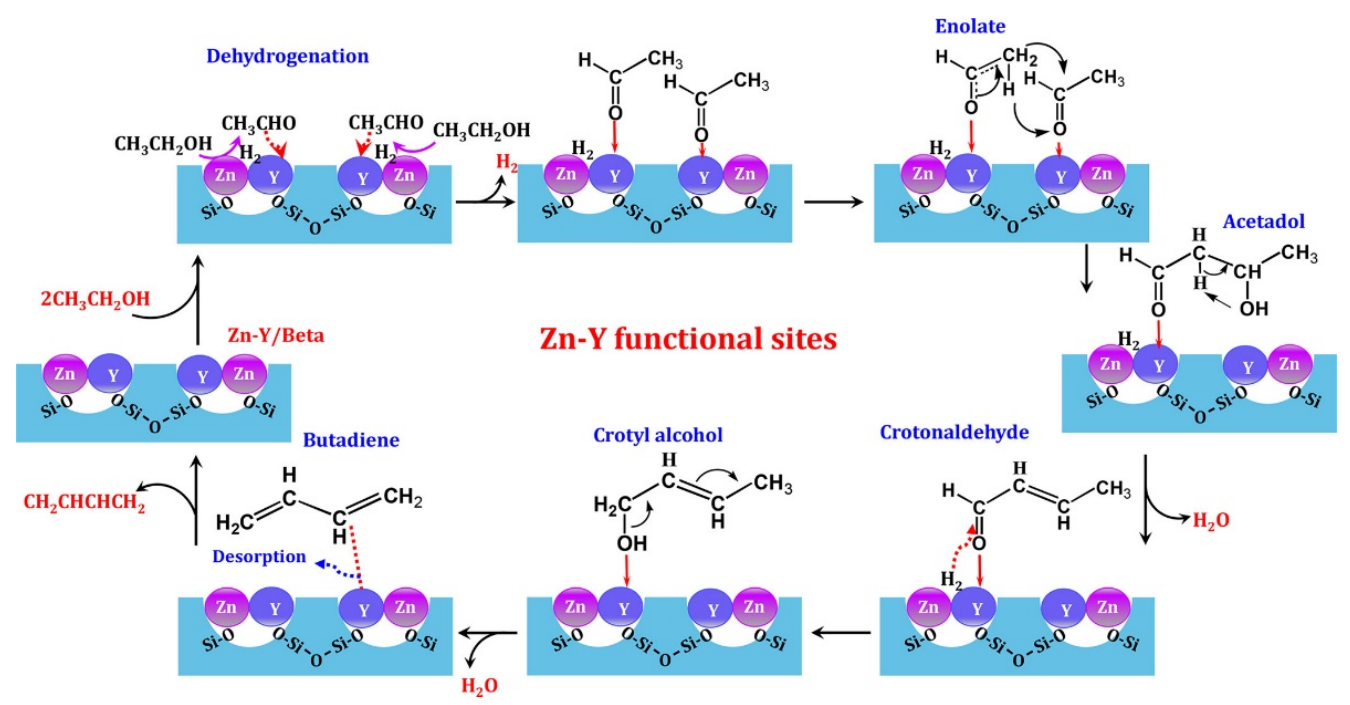

Figure 15. Proposed mechanism of catalytic ethanol conversion into butadiene over the bifunctional Zn-Y/BEA zeolite catalyst. Reprinted with permission from [101]. Copyright 2018 American Chemical Society.

The density functional theory (DFT) calculation with the M06-2X method was used to study the effect of hierarchical nanosheet and conventional ZSM-5 zeolites on the catalytic ethanol dehydration into ethylene [22]. The energy profiles of ethanol dehydration into an ethylene pathway and ethanol conversion to a diethyl ether pathway over the hierarchical nanosheet and conventional ZSM- 5 zeolites were revealed. The external and internal Brønsted acid sites were used as models for the hierarchical and conventional ZSM-5 zeolites, respectively. The results showed that the activation energies of diethyl ether pathway are lower than those of ethylene pathway for the both ZSM-5 zeolites. However, the different values between the activation energies of ethylene and diethyl ether production pathways over the conventional zeolite were higher than that of hierarchical one, indicating that the pathway of ethanol conversion to diethyl ether is more preferable in the conventional ZSM-5 zeolite with respect to the ZSM-5 nanosheet catalyst.

The mechanistic investigation in the catalytic conversion of ethanol to ethylene over the Fe/ZSM-5 zeolite was studied by the DFT approach employing the M06-L method [102]. The large 34T nanocluster model of Fe/ZSM-5 zeolite was used to examine the stepwise and concerted mechanisms. For the stepwise mechanism, the $17.7 \mathrm{kcal} / \mathrm{mol}$ of the activation barrier was used in the initial step to allow the $\mathrm{FeO}^{+}$active species to abstract the hydrogen of the $\mathrm{OH}$ group in the adsorbed ethanol molecule and create the ethoxide-hydroxide intermediate. Subsequently, the ethoxide-hydroxide intermediate was decomposed to produce the ethylene product, and this process was found to be the rate determining step in the stepwise mechanism. The concerted mechanism was the conversion of ethanol to ethylene in the single step without any intermediates. Interestingly, the activation energy of this mechanism was only $32.9 \mathrm{kcal} / \mathrm{mol}$, which is lower than that of the rate-limiting step in the stepwise mechanism $(64.8$ and $63.5 \mathrm{kcal} / \mathrm{mol})$. In addition, the summary of the catalytic behaviors of hierarchical zeolite catalysts is shown in Table S3. 


\section{Conclusions and Future Perspectives}

To date, there have been various hierarchical zeolite catalysts applied in the bioethanol upgrading to renewable monomers. The hierarchical zeolites with nano-crystallized, mesoporous, and nanosheet structures were successfully synthesized by various procedures including the bottom-up or templating approaches and the top-down or post-synthetic treatment methods. The various types of organic templates such as TBPOH, TPOAC, and quaternary ammonium surfactants were systematically used to build the various hierarchical structures. Moreover, there were many post-synthetic treatment procedures, which can construct the additional mesopores in the microporous zeolites such as the desilication, dealumination, and $\mathrm{NH}_{4} \mathrm{~F}$ etching. Furthermore, the metal incorporation into the hierarchical zeolites is an important task to create the suitable active species of each catalytic reaction. The metal incorporation into the zeolites can be done by ion-exchange, wet-impregnation, and one-pot synthesis. After the preparation step, the synthesized hierarchical zeolite catalysts need to be characterized to study the properties of the catalysts, especially the textural or porous and acid-base or active sites properties that can affect the catalytic activities. Most of textural properties were investigated by the gas physisorption technique. However, there are many techniques that can also examine textural or porous properties, such as the QE-TPDA of volatile hydrocarbons and electron tomography. For acid-base properties, the $\mathrm{NH}_{3}$-TPD and FTIR of various molecules adsorption were employed in many reports. The metal active species were analyzed by various techniques, such as XPS, UV-vis, Raman, and XAS spectroscopy. The catalytic behaviors of hierarchical zeolite catalysts in the bioethanol upgrading to monomers can be divided into two parts: catalytic activities and mechanistic studies. The catalytic activities were investigated in various processes including bioethanol dehydration to ethylene, bioethanol conversion to hydrocarbons, and bioethanol conversion to butadiene. The mechanistic studies were examined by various operando techniques and theoretical calculations such as operando DRIFTS and DFT approaches. However, the mechanistic studies are still not enough to fully understand all of the catalytic ethanol conversion to monomers processes, in particular how do the different hierarchical structures affect the catalytic mechanism. Consequently, further insight into the mechanisms should be clearly illustrated in future work.

Practically, bioethanol conversion to monomers over zeolite catalysts at the commercial scale is still rare even though the production amount of bioethanol increases every year, especially in agricultural countries. Moreover, while the attention to EV increases everyday because of environmental issues, the main application of bioethanol is still only a biofuel. Furthermore, the catalytic bioethanol conversion to monomers is an environmentally friendly process because it does not produce any greenhouse gases as by-products, and bioethanol is derived from the most abundant bio-based resources. Consequently, it could be said that the catalytic bioethanol upgrading to renewable monomers is a promising process for both sustainable and economic reasons in the near future.

Supplementary Materials: The following are available online at https: / www.mdpi.com/article/ 10.3390/catal11101162/s1, Table S1: Summary of the preparation perspectives of hierarchical zeolite catalysts, Table S2: Characterization of hierarchical zeolite catalysts, Table S3: Catalytic behaviors of hierarchical zeolites in bioethanol conversion to monomers.

Author Contributions: Conceptualization, P.I. and C.W.; writing—original draft preparation, P.I.; writing-review and editing, P.I. and C.W.; supervision, C.W. All authors have read and agreed to the published version of the manuscript.

Funding: This research was funded by the Vidyasirimedhi Institute of Science and Technology (VISTEC), the Thailand Research Fund (TRF), the Nanocatalysts and Nanomaterials for Sustainable Energy and Environment Research Network (RNN) NANOTEC, the Mid-Career Research Grant 2020 from National Research Council of Thailand (NRCT5-RSA63025-03), the Thailand Science Research and Innovation (TSRI) (FRB640087), and the Energy Conservation and Promotion Fund (grant number: 64-03-0003). 
Acknowledgments: This work was supported by the Vidyasirimedhi Institute of Science and Technology (VISTEC), the Thailand Research Fund (TRF), and the Nanocatalysts and Nanomaterials for Sustainable Energy and Environment Research Network (RNN) NANOTEC. C. W. thanks the MidCareer Research Grant 2020 from National Research Council of Thailand. This work also received financial support from Thailand Science Research and Innovation (TSRI) and Energy Conservation and Promotion Fund Office (ENCON Fund).

Conflicts of Interest: The authors declare no conflict of interest.

\section{References}

1. Zhu, Y.; Romain, C.; Williams, C.K. Sustainable polymers from renewable resources. Nature 2016, 540, 354-362. [CrossRef]

2. Gucbilmez, Y.; Dogu, T.; Balci, S. Ethylene and acetaldehyde production by selective oxidation of ethanol using mesoporous V-MCM-41 catalysts. Ind. Eng. Chem. Res. 2006, 45, 3496-3502. [CrossRef]

3. Capellán-Pérez, I.; Mediavilla, M.; de Castro, C.; Carpintero, Ó.; Miguel, L.J. Fossil fuel depletion and socio-economic scenarios: An integrated approach. Energy 2014, 77, 641-666. [CrossRef]

4. Shafiee, S.; Topal, E. When will fossil fuel reserves be diminished? Energy Policy 2009, 37, 181-189. [CrossRef]

5. Höök, M.; Tang, X. Depletion of fossil fuels and anthropogenic climate change-A review. Energy Policy 2013, 52, 797-809. [CrossRef]

6. Bridges, A.; Felder, F.A.; McKelvey, K.; Niyogi, I. Uncertainty in energy planning: Estimating the health impacts of air pollution from fossil fuel electricity generation. Energy Res. Soc. Sci. 2015, 6, 74-77. [CrossRef]

7. Wang, L.; Templer, R.; Murphy, R.J. Environmental sustainability of bioethanol production from waste papers: Sensitivity to the system boundary. Energy Environ. Sci. 2012, 5, 8281-8293. [CrossRef]

8. $\quad$ Baeyens, J.; Kang, Q.; Appels, L.; Dewil, R.; Lv, Y.; Tan, T. Challenges and opportunities in improving the production of bio-ethanol. Prog. Energy Combust. Sci. 2015, 47, 60-88. [CrossRef]

9. Morone, P.; Strzałkowski, A.; Tani, A. Chapter 2-Biofuel transitions: An overview of regulations and standards for a more sustainable framework. In Biofuels for a More Sustainable Future; Ren, J., Scipioni, A., Manzardo, A., Liang, H., Eds.; Elsevier: Amsterdam, The Netherlands, 2020; pp. 21-46.

10. Mączyńska, J.; Krzywonos, M.; Kupczyk, A.; Tucki, K.; Sikora, M.; Pińkowska, H.; Bączyk, A.; Wielewska, I. Production and use of biofuels for transport in Poland and Brazil-The case of bioethanol. Fuel 2019, 241, 989-996. [CrossRef]

11. Kempton, W.; Letendre, S.E. Electric vehicles as a new power source for electric utilities. Transp. Res. D Transp. Environ. 1997, 2, 157-175. [CrossRef]

12. Hannan, M.A.; Azidin, F.A.; Mohamed, A. Hybrid electric vehicles and their challenges: A review. Renew. Sustain. Energy Rev. 2014, 29, 135-150. [CrossRef]

13. Choopun, W.; Jitkarnka, S. Catalytic activity and stability of HZSM-5 zeolite and hierarchical uniform mesoporous MSU-S ZSM-5 $_{5}$ material during bio-ethanol dehydration. J. Clean. Prod. 2016, 135, 368-378. [CrossRef]

14. Cordero-Lanzac, T.; Aguayo, A.T.; Gayubo, A.G.; Bilbao, J. Influence of HZSM-5-based catalyst deactivation on the performance of different reactor configurations for the conversion of bioethanol into hydrocarbons. Fuel 2021, 302, 121061. [CrossRef]

15. Wang, C.; Zheng, M.; Li, X.; Li, X.; Zhang, T. Catalytic conversion of ethanol into butadiene over high performance LiZnHf-MFI zeolite nanosheets. Green Chem. 2019, 21, 1006-1010. [CrossRef]

16. Haro, P.; Ollero, P.; Trippe, F. Technoeconomic assessment of potential processes for bio-ethylene production. Fuel Process. Technol. 2013, 114, 35-48. [CrossRef]

17. Yakovleva, I.S.; Banzaraktsaeva, S.P.; Ovchinnikova, E.V.; Chumachenko, V.A.; Isupova, L.A. Catalytic dehydration of bioethanol to ethylene. Catal. Ind. 2016, 8, 152-167. [CrossRef]

18. Zhang, M.; Yu, Y. Dehydration of ethanol to ethylene. Ind. Eng. Chem. Res. 2013, 52, 9505-9514. [CrossRef]

19. Zhang, R.; Liu, N.; Lei, Z.; Chen, B. Selective transformation of various nitrogen-containing exhaust gases toward $\mathrm{N}_{2}$ over zeolite catalysts. Chem. Rev. 2016, 116, 3658-3721. [CrossRef]

20. Perez-Ramirez, J.; Christensen, C.H.; Egeblad, K.; Christensen, C.H.; Groen, J.C. Hierarchical zeolites: Enhanced utilisation of microporous crystals in catalysis by advances in materials design. Chem. Soc. Rev. 2008, 37, 2530-2542. [CrossRef]

21. Xi, K.; Cao, S.; Peng, X.; Ducati, C.; Kumar, R.V.; Cheetham, A.K. Carbon with hierarchical pores from carbonized metal-organic frameworks for lithium sulphur batteries. Chem. Commun. 2013, 49, 2192-2194. [CrossRef]

22. Shetsiri, S.; Thivasasith, A.; Saenluang, K.; Wannapakdee, W.; Salakhum, S.; Wetchasat, P.; Nokbin, S.; Limtrakul, J.; Wattanakit, C. Sustainable production of ethylene from bioethanol over hierarchical ZSM-5 nanosheets. Sustain. Energy Fuels 2019, 3, 115-126. [CrossRef]

23. Saenluang, K.; Imyen, T.; Wannapakdee, W.; Suttipat, D.; Dugkhuntod, P.; Ketkaew, M.; Thivasasith, A.; Wattanakit, C. Hierarchical nanospherical ZSM-5 nanosheets with uniform Al distribution for alkylation of benzene with ethanol. ACS Appl. Nano Mater. 2020, 3, 3252-3263. [CrossRef]

24. Zhao, T.; Li, F.; Yu, H.; Ding, S.; Li, Z.; Huang, X.; Li, X.; Wei, X.; Wang, Z.; Lin, H. Synthesis of mesoporous ZSM-5 zeolites and catalytic cracking of ethanol and oleic acid into light olefins. Appl. Catal. A Gen. 2019, 575, 101-110. [CrossRef] 
25. Tarach, K.A.; Tekla, J.; Makowski, W.; Filek, U.; Mlekodaj, K.; Girman, V.; Choi, M.; Góra-Marek, K. Catalytic dehydration of ethanol over hierarchical ZSM-5 zeolites: Studies of their acidity and porosity properties. Catal. Sci. Technol. 2016, 6, 3568-3584. [CrossRef]

26. Ramasamy, K.K.; Zhang, H.; Sun, J.; Wang, Y. Conversion of ethanol to hydrocarbons on hierarchical HZSM-5 zeolites. Catal. Today 2014, 238, 103-110. [CrossRef]

27. Saenluang, K.; Thivasasith, A.; Dugkhuntod, P.; Pornsetmetakul, P.; Salakhum, S.; Namuangruk, S.; Wattanakit, C. In situ synthesis of Sn-beta zeolite nanocrystals for glucose to hydroxymethylfurfural (HMF). Catalysts 2020, 10, 1249. [CrossRef]

28. Astafan, A.; Benghalem, M.A.; Pouilloux, Y.; Patarin, J.; Bats, N.; Bouchy, C.; Daou, T.J.; Pinard, L. Particular properties of the coke formed on nano-sponge *BEA zeolite during ethanol-to-hydrocarbons transformation. J. Catal. 2016, 336, 1-10. [CrossRef]

29. Yang, G.; Wei, Y.; Xu, S.; Chen, J.; Li, J.; Liu, Z.; Yu, J.; Xu, R. Nanosize-enhanced lifetime of SAPO-34 catalysts in methanol-to-olefin reactions. J. Phys. Chem. C 2013, 117, 8214-8222. [CrossRef]

30. Guan, B.; Zhan, R.; Lin, H.; Huang, Z. Review of state of the art technologies of selective catalytic reduction of $\mathrm{NO}_{\mathrm{x}}$ from diesel engine exhaust. Appl. Therm. Eng. 2014, 66, 395-414. [CrossRef]

31. Yutthalekha, T.; Wattanakit, C.; Warakulwit, C.; Wannapakdee, W.; Rodponthukwaji, K.; Witoon, T.; Limtrakul, J. Hierarchical FAU-type zeolite nanosheets as green and sustainable catalysts for benzylation of toluene. J. Clean. Prod. 2017, 142, 1244-1251. [CrossRef]

32. Takata, T.; Tsunoji, N.; Takamitsu, Y.; Sadakane, M.; Sano, T. Nanosized CHA zeolites with high thermal and hydrothermal stability derived from the hydrothermal conversion of FAU zeolite. Microporous Mesoporous Mater. 2016, 225, 524-533. [CrossRef]

33. Zhang, X.; Liu, D.; Xu, D.; Asahina, S.; Cychosz Katie, A.; Agrawal Kumar, V.; Al Wahedi, Y.; Bhan, A.; Al Hashimi, S.; Terasaki, O.; et al. Synthesis of self-pillared zeolite nanosheets by repetitive branching. Science 2012, 336, 1684-1687. [CrossRef]

34. Souza de Carvalho Filho, J.F.; Maciel Pereira, M.; Gomes Aranda, D.A.; Monnerat Araujo Ribeiro de Almeida, J.; Falabella Sousa-Aguiar, E.; Nothaft Romano, P. Application of response surface methodology for ethanol conversion into hydrocarbons using ZSM-5 zeolites. Catalysts 2019, 9, 617. [CrossRef]

35. Wu, C.Y.; Wu, H.S. Ethylene formation from ethanol dehydration using ZSM-5 catalyst. ACS Omega 2017, 2, 4287-4296. [CrossRef]

36. Xin, H.; Li, X.; Fang, Y.; Yi, X.; Hu, W.; Chu, Y.; Zhang, F.; Zheng, A.; Zhang, H.; Li, X. Catalytic dehydration of ethanol over post-treated ZSM-5 zeolites. J. Catal. 2014, 312, 204-215. [CrossRef]

37. Tarach, K.A.; Tekla, J.; Filek, U.; Szymocha, A.; Tarach, I.; Góra-Marek, K. Alkaline-acid treated zeolite L as catalyst in ethanol dehydration process. Microporous Mesoporous Mater. 2017, 241, 132-144. [CrossRef]

38. Sheng, Q.; Ling, K.; Li, Z.; Zhao, L. Effect of steam treatment on catalytic performance of HZSM-5 catalyst for ethanol dehydration to ethylene. Fuel Process. Technol. 2013, 110, 73-78. [CrossRef]

39. Kuterasinski, L.; Filek, U.; Gackowski, M.; Zimowska, M.; Ruggiero-Mikolajczyk, M.; Jodlowski, P.J. Sonochemically prepared hierarchical MFI-type zeolites as active catalysts for catalytic ethanol dehydration. Ultrason. Sonochem. 2021, 74, 105581. [CrossRef]

40. Klein, A.; Palkovits, R. Influence of structural parameters on the conversion of ethanol into 1,3-butadiene using mesoporous zeolites. Catal. Commun. 2017, 91, 72-75. [CrossRef]

41. Yang, G.; Wang, L.; Jiang, H. Preparation of $\beta$ zeolite with intracrystalline mesoporosity via surfactant -templating strategy and its application in ethanol-acetaldehyde to butadiene. Microporous Mesoporous Mater. 2021, 316, 110949. [CrossRef]

42. Lakiss, L.; Ngoye, F.; Canaff, C.; Laforge, S.; Pouilloux, Y.; Qin, Z.; Tarighi, M.; Thomas, K.; Valtchev, V.; Vicente, A.; et al. On the remarkable resistance to coke formation of nanometer-sized and hierarchical MFI zeolites during ethanol to hydrocarbons transformation. J. Catal. 2015, 328, 165-172. [CrossRef]

43. Zhang, N.; Mao, D.; Zhai, X. Selective conversion of bio-ethanol to propene over nano-HZSM-5 zeolite: Remarkably enhanced catalytic performance by fluorine modification. Fuel Process. Technol. 2017, 167, 50-60. [CrossRef]

44. Qin, Z.; Melinte, G.; Gilson, J.P.; Jaber, M.; Bozhilov, K.; Boullay, P.; Mintova, S.; Ersen, O.; Valtchev, V. The mosaic structure of zeolite crystals. Angew. Chem. Int. Ed. Engl. 2016, 55, 15049-15052. [CrossRef]

45. Qin, Z.; Pinard, L.; Benghalem, M.A.; Daou, T.J.; Melinte, G.; Ersen, O.; Asahina, S.; Gilson, J.-P.; Valtchev, V. Preparation of single-crystal "house-of-cards"-like ZSM-5 and their performance in ethanol-to-hydrocarbon conversion. Chem. Mater. 2019, 31, 4639-4648. [CrossRef]

46. Fang, Z.; Murayama, H.; Zhao, Q.; Liu, B.; Jiang, F.; Xu, Y.; Tokunaga, M.; Liu, X. Selective mild oxidation of methane to methanol or formic acid on Fe-MOR catalysts. Catal. Sci. Technol. 2019, 9, 6946-6956. [CrossRef]

47. Yao, J.; Feng, X.; Fan, J.; He, Y.; Kosol, R.; Zeng, Y.; Liu, G.; Ma, Q.; Yang, G.; Tsubaki, N. Effects of mordenite zeolite catalyst synthesis conditions on dimethyl ether carbonylation. Microporous Mesoporous Mater. 2020, 306, 110431. [CrossRef]

48. Gomes, G.J.; Costa, M.B.; Bittencourt, P.R.S.; Zalazar, M.F.; Arroyo, P.A. Catalytic improvement of biomass conversion: Effect of adding mesoporosity on MOR zeolite for esterification with oleic acid. Renew. Energy 2021, 178, 1-12. [CrossRef]

49. Iadrat, P.; Horii, N.; Atithep, T.; Wattanakit, C. Effect of pore connectivity of pore-opened hierarchical MOR zeolites on catalytic behaviors and coke formation in ethanol dehydration. ACS Appl. Mater. Interfaces 2021, 13, 8294-8305. [CrossRef]

50. Khatamian, M.; Saket Oskoui, M.; Darbandi, M. Synthesis and characterization of aluminium-free ZSM-5 type chromosilicates in different alkaline systems and investigation of their pore structures. Microporous Mesoporous Mater. 2013, 182, 50-61. [CrossRef]

51. Ji, Y.; Yang, H.; Yan, W. Effect of alkali metal cations modification on the acid/basic properties and catalytic activity of ZSM-5 in cracking of supercritical n-dodecane. Fuel 2019, 243, 155-161. [CrossRef] 
52. Kostyniuk, A.; Bajec, D.; Djinović, P.; Likozar, B. One-step synthesis of glycidol from glycerol in a gas-phase packed-bed continuous flow reactor over HZSM-5 zeolite catalysts modified by $\mathrm{CsNO}_{3}$. Chem. Eng. J. 2020, 394, 124945. [CrossRef]

53. Ketkaew, M.; Klinyod, S.; Saenluang, K.; Rodaum, C.; Thivasasith, A.; Kidkhunthod, P.; Wattanakit, C. Fine-tuning the chemical state and acidity of ceria incorporated in hierarchical zeolites for ethanol dehydration. Chem. Commun. 2020, 56, 11394-11397. [CrossRef] [PubMed]

54. Kim, H.; Numan, M.; Jo, C. Catalytic dehydration of ethanol over $\mathrm{WO}_{\mathrm{x}}$ nanoparticles supported on MFI (mobile five) zeolite nanosheets. Catalysts 2019, 9, 670. [CrossRef]

55. Vondrová, P.; Tišler, Z.; Kocík, J.; de Paz Carmona, H.; Murat, M. Comparison of doped ZSM-5 and ferrierite catalysts in the dehydration of bioethanol to ethylene in a flow reactor. React. Kinet. Mech. Catal. 2021, 132, 449-462. [CrossRef]

56. Sarve, D.T.; Singh, S.K.; Ekhe, J.D. Kinetic and mechanistic study of ethanol dehydration to diethyl ether over Ni-ZSM-5 in a closed batch reactor. React. Kinet. Mech. Catal. 2020, 131, 261-281. [CrossRef]

57. Liu, C.-Y.; Struwe, K.; Lee, C.-H.; Chuang, H.-Y.; Sauer, J.; Yu, J.C.-C.; Nguyen, V.-H.; Huang, C.-W.; Wu, J.C.S. Ethanol conversion to selective high-value hydrocarbons over Ni/HZSM-5 zeolite catalyst. Catal. Commun. 2020, 144, 106067. [CrossRef]

58. Wang, S.; He, B.; Tian, R.; Sun, C.; Dai, R.; Li, X.; Wu, X.; An, X.; Xie, X. Ni-hierarchical Beta zeolite catalysts were applied to ethanol steam reforming: Effect of sol gel method on loading Ni and the role of hierarchical structure. Mol. Catal. 2018, 453, 64-73. [CrossRef]

59. Grzybek, G.; Greluk, M.; Tarach, K.; Pyra, K.; Słowik, G.; Rotko, M.; Góra-Marek, K. Bioethanol steam reforming over cobaltcontaining USY and ZSM-5 commercial zeolite catalysts. Front. Mater. 2020, 7, 37-50. [CrossRef]

60. da Costa-Serra, J.F.; Navarro, M.T.; Rey, F.; Chica, A. Sustainable production of hydrogen by steam reforming of ethanol using cobalt supported on nanoporous zeolitic material. Nanomaterials 2020, 10, 1934. [CrossRef]

61. Narula, C.K.; Li, Z.; Casbeer, E.M.; Geiger, R.A.; Moses-Debusk, M.; Keller, M.; Buchanan, M.V.; Davison, B.H. Heterobimetallic zeolite, InV-ZSM-5, enables efficient conversion of biomass derived ethanol to renewable hydrocarbons. Sci. Rep. 2015, 5, 16039. [CrossRef]

62. Said, S.; Aman, D.; Riad, M.; Mikhail, S. MoZn/ $\mathrm{AlPO}_{4}-5$ zeolite: Preparation, structural characterization and catalytic dehydration of ethanol. J. Solid State Chem. 2020, 287, 121335. [CrossRef]

63. Sushkevich, V.L.; Ivanova, I.I. Ag-promoted ZrBEA zeolites obtained by post-synthetic modification for conversion of ethanol to butadiene. ChemSusChem 2016, 9, 2216-2225. [CrossRef] [PubMed]

64. Li, X.; Pang, J.; Wang, C.; Li, L.; Pan, X.; Zheng, M.; Zhang, T. Conversion of ethanol to 1,3-butadiene over high-performance $\mathrm{Mg}-\mathrm{ZrO}_{\mathrm{x}} / \mathrm{MFI}$ nanosheet catalysts via the two-step method. Green Chem. 2020, 22, 2852-2861. [CrossRef]

65. Kyriienko, P.I.; Larina, O.V.; Soloviev, S.O.; Orlyk, S.M.; Calers, C.; Dzwigaj, S. Ethanol conversion into 1,3-butadiene by the Lebedev method over MTaSiBEA zeolites ( $\mathrm{M}=\mathrm{Ag}, \mathrm{Cu}, \mathrm{Zn})$. ACS Sustain. Chem. Eng. 2017, 5, 2075-2083. [CrossRef]

66. Kostyniuk, A.; Bajec, D.; Djinović, P.; Likozar, B. Allyl alcohol production by gas phase conversion reactions of glycerol over bifunctional hierarchical zeolite-supported bi- and tri-metallic catalysts. Chem. Eng. J. 2020, 397, 125430. [CrossRef]

67. Karanwal, N.; Sibi, M.G.; Khan, M.K.; Myint, A.A.; Chan Ryu, B.; Kang, J.W.; Kim, J. Trimetallic Cu-Ni-Zn/H-ZSM-5 catalyst for the one-pot conversion of levulinic acid to high-yield 1,4-pentanediol under mild conditions in an aqueous medium. ACS Catal. 2021, 11, 2846-2864. [CrossRef]

68. Li, J.; Xiao, G.; Guo, Z.; Lin, B.; Hu, Y.; Fu, M.; Ye, D. ZSM-5-supported V-Cu bimetallic oxide catalyst for remarkable catalytic oxidation of toluene in coal-fired flue gas. Chem. Eng. J. 2021, 419, 129675. [CrossRef]

69. Wu, Z.; Zhang, J.; Su, Z.; Wang, P.; Tan, T.; Xiao, F.-S. Low-temperature dehydration of ethanol to ethylene over Cu-zeolite catalysts synthesized from Cu-tetraethylenepentamine. Ind. Eng. Chem. Res. 2020, 59, 17300-17306. [CrossRef]

70. Dugkhuntod, P.; Maineawklang, N.; Saenluang, K.; Salakhum, S.; Rodaum, C.; Pornsetmetakul, P.; Wattanakit, C. Synthesis and characterization of $\mathrm{Sn}, \mathrm{Ge}$, and $\mathrm{Zr}$ isomorphous substituted MFI nanosheets for glucose isomerization to fructose. ChemPlusChem 2021, in press. [CrossRef]

71. Makowski, W. Quasi-equilibrated temperature programmed desorption and adsorption: A new method for determination of the isosteric adsorption heat. Thermochim. Acta 2007, 454, 26-32. [CrossRef]

72. Mlekodaj, K.; Tarach, K.; Datka, J.; Góra-Marek, K.; Makowski, W. Porosity and accessibility of acid sites in desilicated ZSM-5 zeolites studied using adsorption of probe molecules. Microporous Mesoporous Mater. 2014, 183, 54-61. [CrossRef]

73. Soh, J.C.; Chong, S.L.; Hossain, S.S.; Cheng, C.K. Catalytic ethylene production from ethanol dehydration over non-modified and phosphoric acid modified Zeolite H-Y (80) catalysts. Fuel Process. Technol. 2017, 158, 85-95. [CrossRef]

74. Nguyen, T.T.N.; Ruaux, V.; Massin, L.; Lorentz, C.; Afanasiev, P.; Maugé, F.; Bellière-Baca, V.; Rey, P.; Millet, J.M.M. Synthesis, characterization and study of lanthanum phosphates as light alcohols dehydration catalysts. Appl. Catal. B Environ. 2015, 166-167, 432-444. [CrossRef]

75. Suttipat, D.; Saenluang, K.; Wannapakdee, W.; Dugkhuntod, P.; Ketkaew, M.; Pornsetmetakul, P.; Wattanakit, C. Fine-tuning the surface acidity of hierarchical zeolite composites for methanol-to-olefins (MTO) reaction. Fuel 2021, 286, 119306. [CrossRef]

76. Damyanova, S.; Centeno, M.A.; Petrov, L.; Grange, P. Fourier transform infrared spectroscopic study of surface acidity by pyridine adsorption on $\mathrm{Mo} / \mathrm{ZrO}_{2}-\mathrm{SiO}_{2}\left(\mathrm{Al}_{2} \mathrm{O}_{3}\right)$ catalysts. Spectrochim. Acta A Mol. Biomol. Spectrosc. 2001, 57, 2495-2501. [CrossRef]

77. Travert, A.; Vimont, A.; Sahibed-Dine, A.; Daturi, M.; Lavalley, J.-C. Use of pyridine CH(D) vibrations for the study of Lewis acidity of metal oxides. Appl. Catal. A Gen. 2006, 307, 98-107. [CrossRef] 
78. Góra-Marek, K.; Tarach, K.; Choi, M. 2,6-Di-tert-butylpyridine sorption approach to quantify the external acidity in hierarchical zeolites. J. Phys. Chem. C 2014, 118, 12266-12274. [CrossRef]

79. Sadowska, K.; Góra-Marek, K.; Datka, J. Accessibility of acid sites in hierarchical zeolites: Quantitative IR studies of pivalonitrile adsorption. J. Phys. Chem. C 2013, 117, 9237-9244. [CrossRef]

80. Sushkevich, V.L.; Vimont, A.; Travert, A.; Ivanova, I.I. Spectroscopic evidence for open and closed Lewis acid sites in ZrBEA zeolites. J. Phys. Chem. C 2015, 119, 17633-17639. [CrossRef]

81. Hadjiivanov, K.I.; Vayssilov, G.N. Characterization of oxide surfaces and zeolites by carbon monoxide as an IR probe molecule. In Advances in Catalysis; Academic Press: Cambridge, MA, USA, 2002; Volume 47, pp. 307-511.

82. Huang, M.; Kaliaguine, S. Zeolite basicity characterized by pyrrole chemisorption: An infrared study. J. Chem. Soc. Faraday Trans. 1992, 88, 751-758. [CrossRef]

83. Angelici, C.; Meirer, F.; van der Eerden, A.M.J.; Schaink, H.L.; Goryachev, A.; Hofmann, J.P.; Hensen, E.J.M.; Weckhuysen, B.M.; Bruijnincx, P.C.A. Ex situ and operando studies on the role of copper in Cu-promoted $\mathrm{SiO}_{2}-\mathrm{MgO}$ catalysts for the Lebedev ethanol-to-butadiene process. ACS Catal. 2015, 5, 6005-6015. [CrossRef]

84. Reddy, G.R.; Balasubramanian, S.; Chennakesavulu, K. Zeolite encapsulated active metal composites and their photocatalytic studies for rhodamine-B, reactive red-198 and chloro-phenols. RSC Adv. 2015, 5, 81013-81023. [CrossRef]

85. Hutson, N.D.; Reisner, B.A.; Yang, R.T.; Toby, B.H. Silver ion-exchanged zeolites Y, X, and low-silica X: Observations of thermally induced cation/cluster migration and the resulting effects on the equilibrium adsorption of nitrogen. Chem. Mater. 2000, 12, 3020-3031. [CrossRef]

86. Ju, W.-S.; Matsuoka, M.; Iino, K.; Yamashita, H.; Anpo, M. The local structures of silver(I) ion catalysts anchored within zeolite cavities and their photocatalytic reactivities for the elimination of $\mathrm{N}_{2} \mathrm{O}$ into $\mathrm{N}_{2}$ and $\mathrm{O}_{2}$. J. Phys. Chem. B 2004, 108, 2128-2133. [CrossRef]

87. Dzwigaj, S.; Janas, J.; Mizera, J.; Gurgul, J.; Socha, R.P.; Che, M. Incorporation of copper in SiBEA zeolite as isolated lattice mononuclear $\mathrm{Cu}(\mathrm{II})$ species and its role in selective catalytic reduction of NO by ethanol. Catal. Lett. 2008, 126, 36-42. [CrossRef]

88. Gong, T.; Qin, L.; Lu, J.; Feng, H. ZnO modified ZSM-5 and Y zeolites fabricated by atomic layer deposition for propane conversion. Phys. Chem. Chem. Phys. 2016, 18, 601-614. [CrossRef]

89. Newalkar, B.L.; Olanrewaju, J.; Komarneni, S. Microwave-hydrothermal synthesis and characterization of zirconium substituted SBA-15 mesoporous silica. J. Phys. Chem. B 2001, 105, 8356-8360. [CrossRef]

90. Tang, Y.; Zong, E.; Wan, H.; Xu, Z.; Zheng, S.; Zhu, D. Zirconia functionalized SBA-15 as effective adsorbent for phosphate removal. Microporous Mesoporous Mater. 2012, 155, 192-200. [CrossRef]

91. Gao, X.; Fierro, J.L.G.; Wachs, I.E. Structural characteristics and catalytic properties of highly dispersed $\mathrm{ZrO}_{2} / \mathrm{SiO}_{2}$ and $\mathrm{V}_{2} \mathrm{O}_{5} / \mathrm{ZrO}_{2} / \mathrm{SiO}_{2}$ catalysts. Langmuir 1999, 15, 3169-3178. [CrossRef]

92. Yamazoe, S.; Hitomi, Y.; Shishido, T.; Tanaka, T. XAFS study of tungsten $\mathrm{L}_{1}$ - and $\mathrm{L}_{3}$-edges: Structural analysis of $\mathrm{WO}_{3}$ species loaded on $\mathrm{TiO}_{2}$ as a catalyst for photo-oxidation of $\mathrm{NH}_{3}$. J. Phys. Chem. C 2008, 112, 6869-6879. [CrossRef]

93. Bi, J.; Guo, X.; Liu, M.; Wang, X. High effective dehydration of bio-ethanol into ethylene over nanoscale HZSM-5 zeolite catalysts. Catal. Today 2010, 149, 143-147. [CrossRef]

94. Li, X.; Rezaei, F.; Ludlow, D.K.; Rownaghi, A.A. Synthesis of SAPO-34@ZSM-5 and SAPO-34@silicalite-1 core-shell zeolite composites for ethanol dehydration. Ind. Eng. Chem. Res. 2018, 57, 1446-1453. [CrossRef]

95. Ramasamy, K.K.; Wang, Y. Ethanol conversion to hydrocarbons on HZSM-5: Effect of reaction conditions and $\mathrm{Si} / \mathrm{Al}$ ratio on the product distributions. Catal. Today 2014, 237, 89-99. [CrossRef]

96. Pomalaza, G.; Arango Ponton, P.; Capron, M.; Dumeignil, F. Ethanol-to-butadiene: The reaction and its catalysts. Catal. Sci. Technol. 2020, 10, 4860-4911. [CrossRef]

97. Kadam, S.A.; Shamzhy, M.V. IR Operando study of ethanol dehydration over MFI zeolite. Catal. Today 2018, 304, 51-57. [CrossRef]

98. Kadam, S.A.; Shamzhy, M.V. IR Operando study of ethanol dehydration over MFI zeolites: Structure-activity relationships. J. Phys. Chem. C 2018, 122, 24055-24067. [CrossRef]

99. Zhou, X.; Wang, C.; Chu, Y.; Xu, J.; Wang, Q.; Qi, G.; Zhao, X.; Feng, N.; Deng, F. Observation of an oxonium ion intermediate in ethanol dehydration to ethene on zeolite. Nat. Commun. 2019, 10, 1961. [CrossRef]

100. Van der Borght, K.; Galvita, V.V.; Marin, G.B. Ethanol to higher hydrocarbons over Ni, Ga, Fe-modified ZSM-5: Effect of metal content. Appl. Catal. A Gen. 2015, 492, 117-126. [CrossRef]

101. Yan, T.; Dai, W.; Wu, G.; Lang, S.; Hunger, M.; Guan, N.; Li, L. Mechanistic insights into one-step catalytic conversion of ethanol to butadiene over bifunctional Zn-Y/beta zeolite. ACS Catal. 2018, 8, 2760-2773. [CrossRef]

102. Maihom, T.; Khongpracha, P.; Sirijaraensre, J.; Limtrakul, J. Mechanistic studies on the transformation of ethanol into ethene over Fe-ZSM-5 zeolite. ChemPhysChem 2013, 14, 101-107. [CrossRef] 